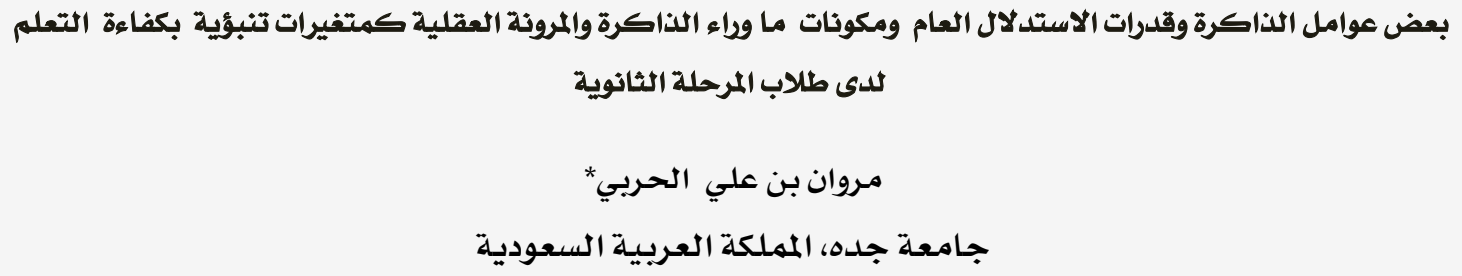

\title{
Some Memory Factors and Reasoning General, Meta Memory Components and Mental Flexibility as Predictive Learning Efficiency among High School Students
}

\author{
Marwan A. Alharbi* \\ University of Jeddah, Kingdom of Saudi Arabia
}

This study aimed to detect differences between the efficiency of different variables learning factors memory (visual memory and memory), reasoning capabilities, Meta memory Components and mental flexibility, in addition to the disclosure of the best predictors of learning efficiency by independent variables under study. The study sample included 202 high school students. The results indicated that there were statistically significant differences 0.01among students of different level of learning efficiency standards, visual memory, prepare arithmetic, readiness mathematics ability to calculations necessary and creators of estimation, memory function and assess the use of strategies to remember and flexibility mental. addition to and that can be interpreted approximately $99.6 \%$ of the variance on the variable efficiency learning high school students learning visual memory and the memory capacity of reasoning Meta memory Components and mental flexibility (except Meta memory Components).

Keywords: visual memory, memory spa, reasoning general, meta memory components, mental flexibility, learning efficiency.

\section{*net22001@hotmail.com}


فرصة التوجيه الذاتي أثناء التعلهم وضعف عملية

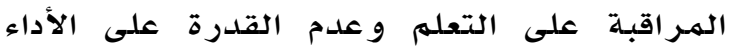
الجيد ويضطر المتعلهم إلى التخمين واستخدام استراتيجيات تعلهم غير مناسبـة مهـا يؤدي إلى مزيد من الأخطاء أو التخلي عن الأداء؛ وعليه

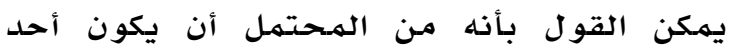
الأسباب الرئيسلة لعدم كفاءة التعلهم لدى الطلاب

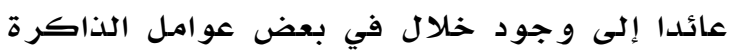

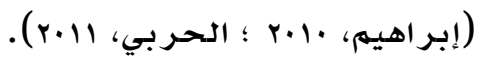

و من خلال سلسـلة البحوث والدراسات المعرفية

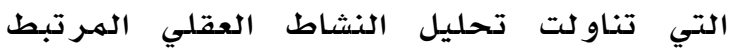
بالذاكرة برز مفهوم عوامل الذاكرة، وهي

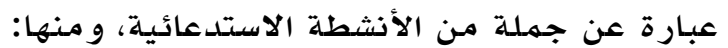

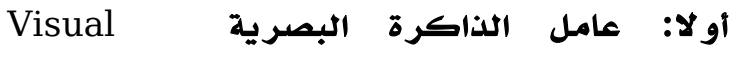
Memory على تذكر ترتيب أشكال وتذكر موضعها

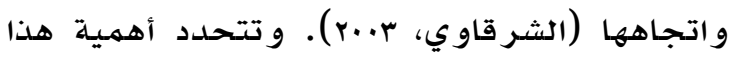

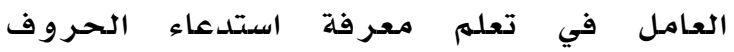
الهجائية و المفردات المطبوعة وكذلك مهارات

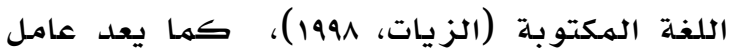
الذاكرة البصرية من أكثر العمليات المعرفية

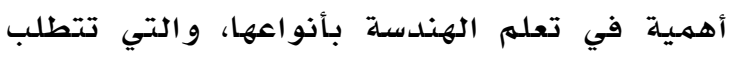
ضرورة تلذكرهم لهـختلف الأشكال الهندسية.

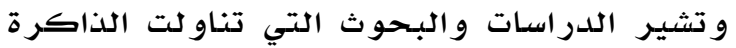

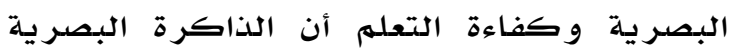
تعلب دورا مهما في التعلم خاصة في مقرري

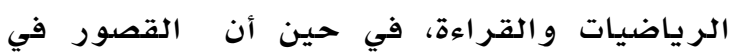

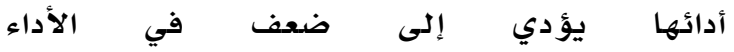

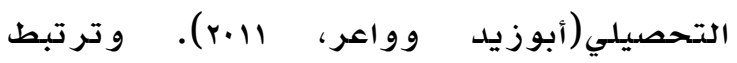
الذاكرة البصرية أيضا بكفاءة التعلم في مقرد الرياضيات وتعد الذاكرة البصرية منبئًا جيدا بكفاءة التعلم لدى طلاب الصف الدرابع العابع الابتدائي

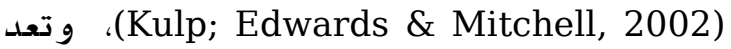
من مصادر الفروق بين الطلاب في مستويات

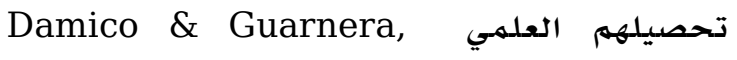
(2005)، كها يمكنها أن تتنباً بتباين مستويات كفاءة التعلم لدى طلاب المرحلة الابتدائية

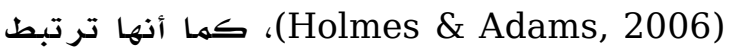

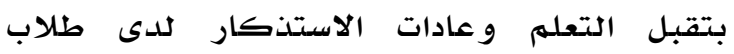

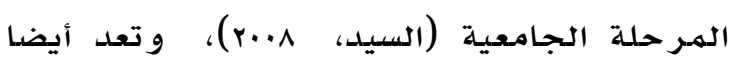

يعد التعلهم عملية معقدة تؤثر وتتأثر بالعديد من العوامل المهختلفــة. وفـي ضــوء اعتبـار المعـدل

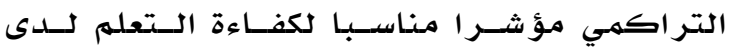

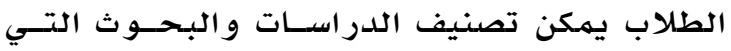

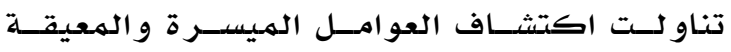
لحصدول الطلاب على معدلات تراكمية مر تفعسة الكية

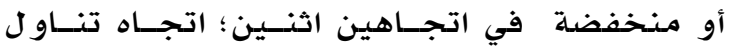

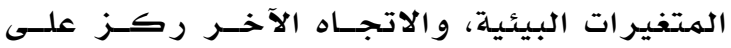

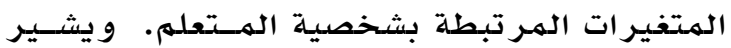

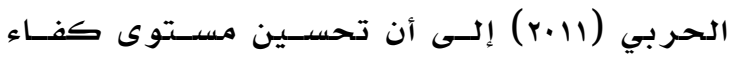

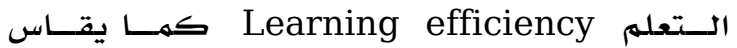
بالمعسـدل التر اكهــي سـيكون أفضـل فــي حالسة

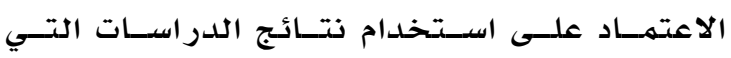
تنـاو لت العوامل المعرفية الهؤثرة فـي مســـوى التحصيل في إطار شمولي من ثأنه المساهمـة في

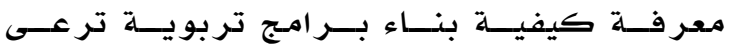
شر يحتي مـر تفعي و منـخفضي التحصيل.

ويرجـع اهتمام ميداني علهم النفس التربوي و علم النفس المعرفي بهوضوع الذاكرة كونها تعد

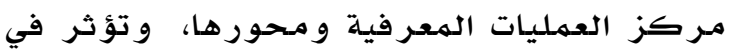
كل ما هو معرفي وعلى كافة الأنشطة العقلية

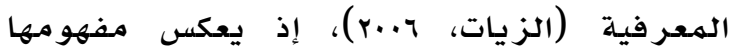

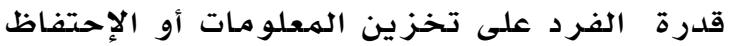

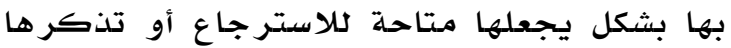

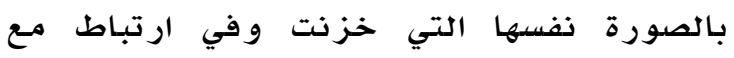
الهثيرات نفسها التي ارتبطت بها عند تعلمها.

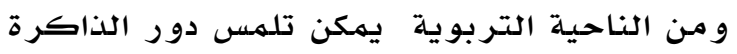

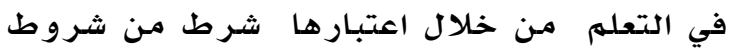

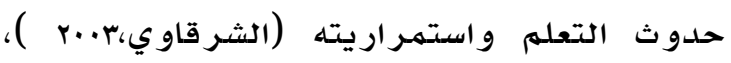
كما أنها تؤدي دورا مههما في القراءة والكابها والكتابة

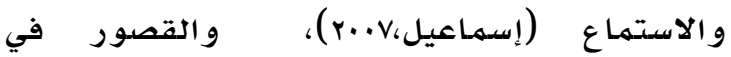

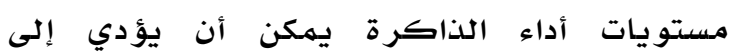
صعوبة في عمليّة التعلهم ( \&cNamara \&)

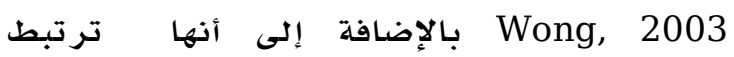

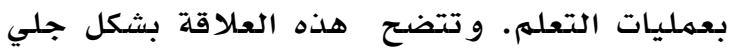
عند تقديم المادة التعليمية للمتعلهم بشكل مفصل و مفهوم و ذلك عن طريق الربط بين المعلو مـات

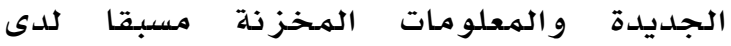

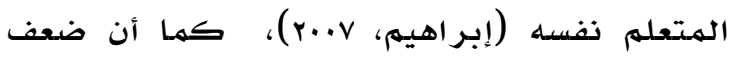

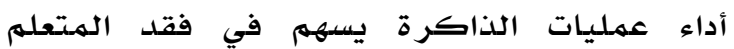


التفكير (خليل، r.lr)، الهعر فية الضرورية للطلاب خاصدة في العصر

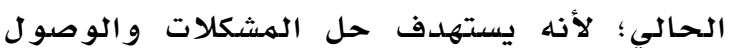
إلى اتخاذ القرارات أو إصدار الأحكام عبر عملية

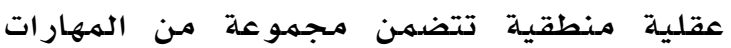
التي يتتم فيها الاستفادة من المعلوميكات المتاحة

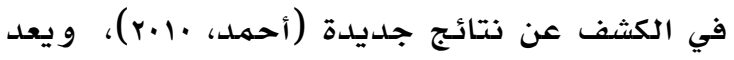
الاستدلال العام أيضا من العمليات الرئيسلة للتعلهم الإنساني التي تسهم في تقديه تفسيرات دقيقة و منطقية كلأحداث والهمواقف، كما أنه يسهمه في لهي

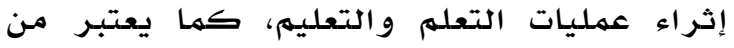

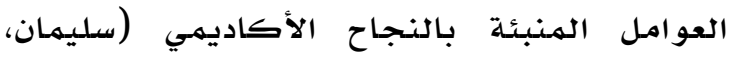

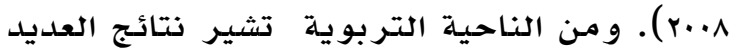
من البحوث و الدراسات إلى أن القدرة الاستدلالية

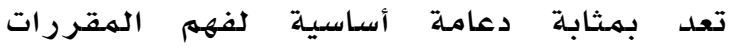

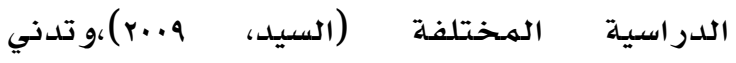

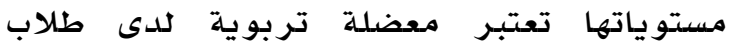

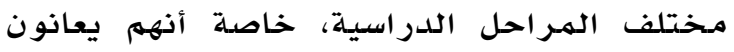

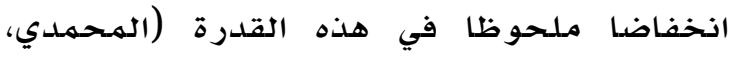

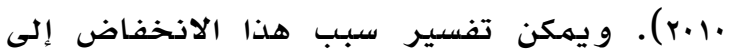
طبيعة و نوعية الأساليب المستخلدمـة في طرق

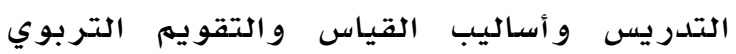

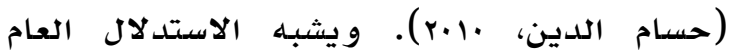
كثيرا الاستدلال المنطقي القياسي حيث الن أن

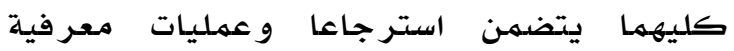

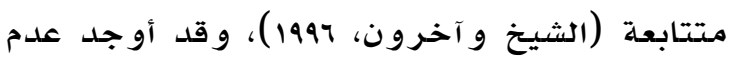

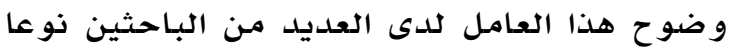
مـن الخلط بينه وبين القدرة العددية نظير التشابه في المقاييس والأساليب التي تقيس كلا

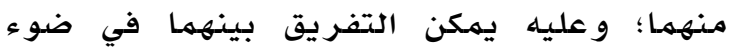

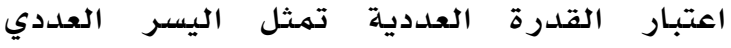

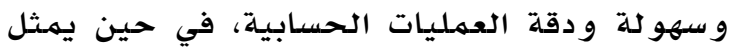

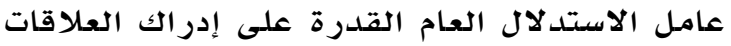
التي تربط بين الأثياء و الفهم للمعاني.

ويعرف الاستدلال العام بأنه القدرة على فهم وتركيب المشكلة حتى يستطيع الفرد أن يجد Kaufmana; DeYoungb; الحل المناسب لها و

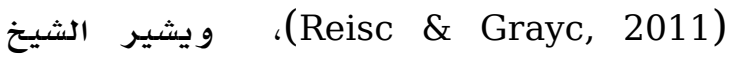
و آخرون (1997) إلى أن اختبار الاستدلال العام

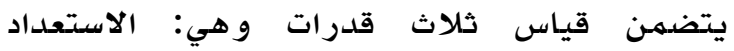

أحد أسباب انخفاض مستوى كفاءة التعلم لدى طلاب المرحلتين الابتدائية والمتوسطة، ومن العوامل المعرفية التي تسهم و وبشكل فعال في والهين Sarver et التنبؤ المبكر بمستوى كفاءة التعلهم .(al., 2012)

ثانيا: عامل مدى الذاكرة Memory Span: ويشير هذا العامل إلى قدرة الفرد على الاستدعاء

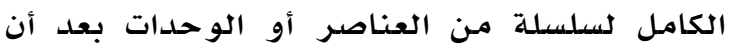

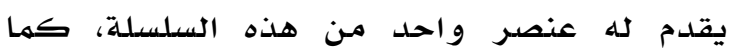
يشير هذا العامل إلى قدرة الفرد على تمييز

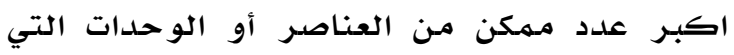

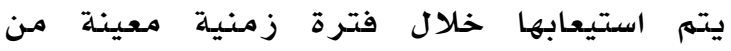

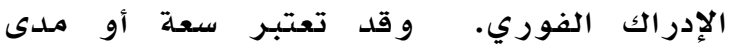

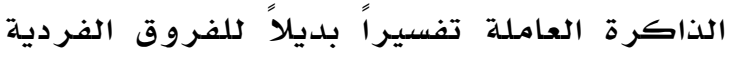
في القدرات العقلية من خلال تسليط الضدوء

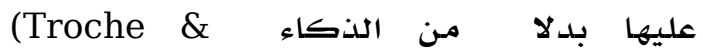

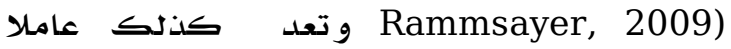
مهما في تحديد معدل تعلهم وتقييم مستويات أداء الطلاب في مجال العلوم النظرية و التطبيقية

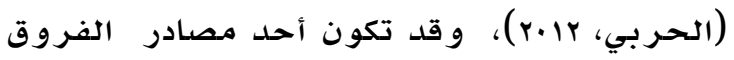

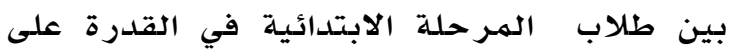
الكتابة (Bourke \& Adams, 2003)، و وأحد مصادر الفروق في القدرة على الاستدعاء بين

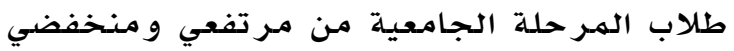

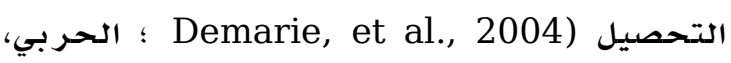

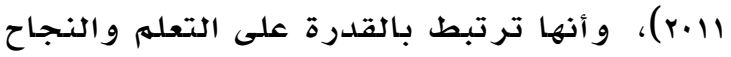

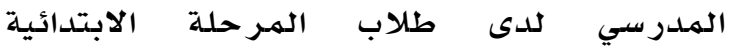
Thompson \& Gathercole Dolores, ) 2008). و تعد مؤشرا جيد للتنبؤ بالتفوق لدى

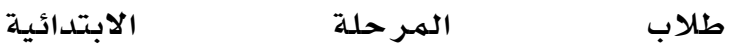
(Alloway \& Alloway, 2010 Bull; Espy \&

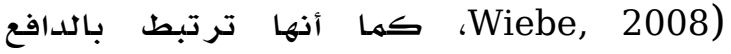

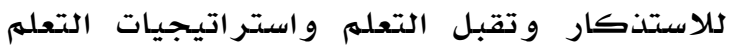

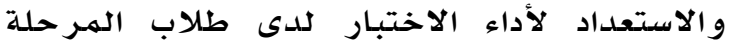

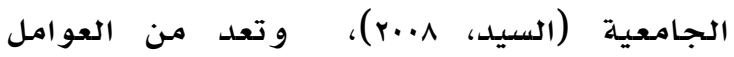

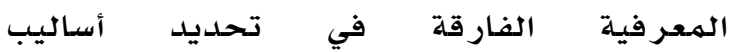

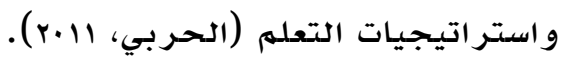
ويرجـع اهتمام الدراسة الحالية بمتغير الاستدلال العام Reasoning General كونه يعد العد العنصر

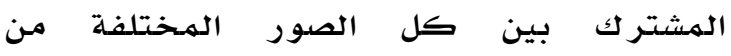


لم لهذا المتغير من أثر مهم في التطور المعر في (لتراي

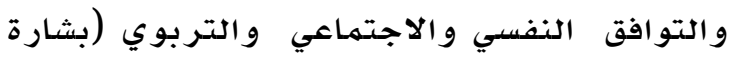

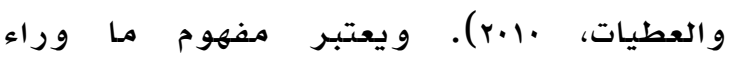

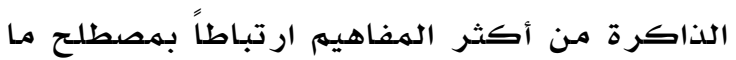

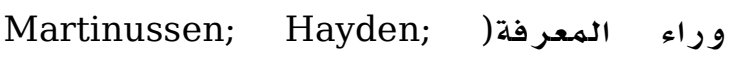
(Johnson \& Tannock, 2005

ويرى فلافل Flavell (2003) أن هذا المفهـوم

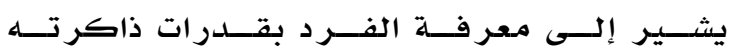

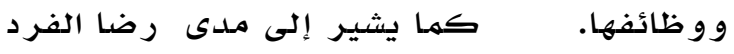

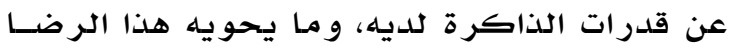

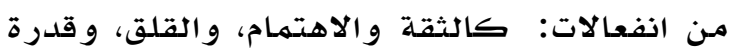

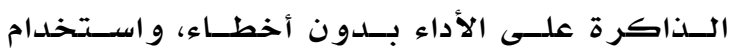

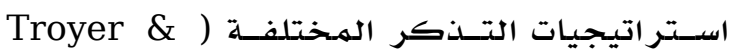

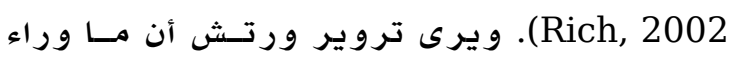

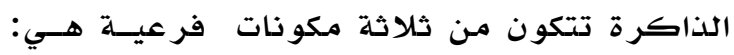

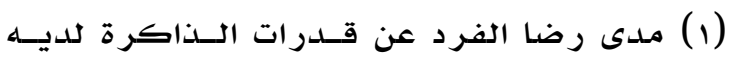

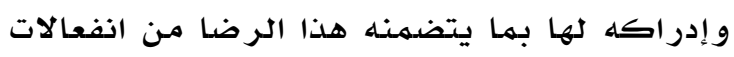

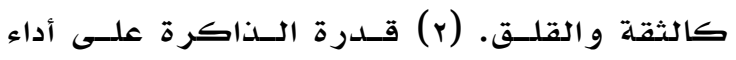

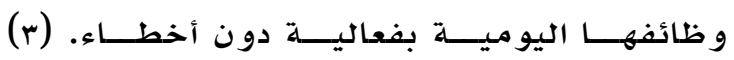

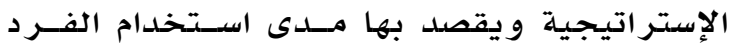

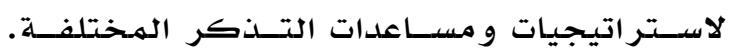

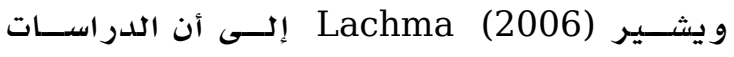

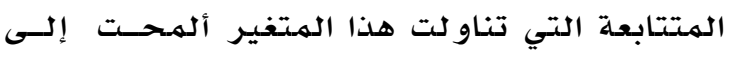

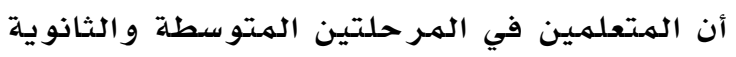

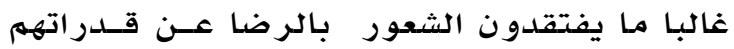

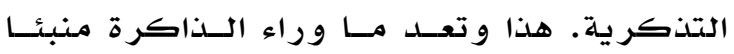

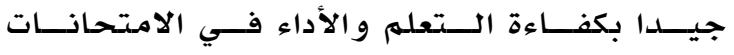
،Rawson, Dunlosky \& Thiede, 2000) و تزيد من أداء عمليات التذكر بشكل أفضل لدى

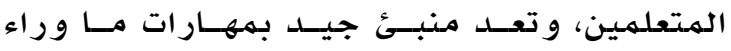

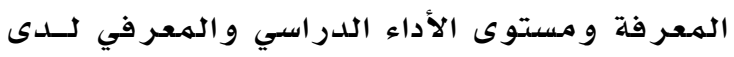

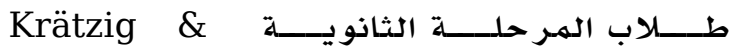

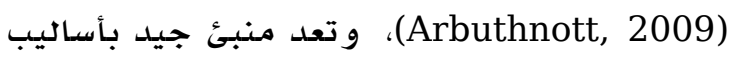

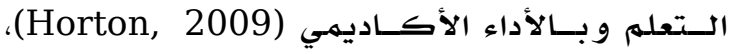

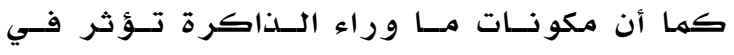

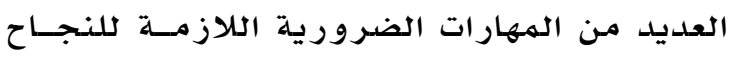

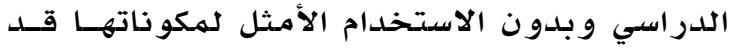

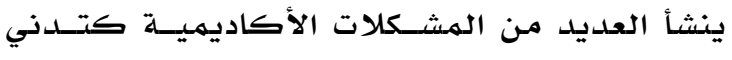

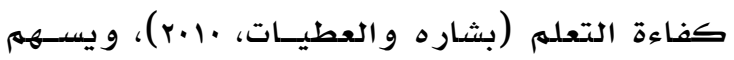

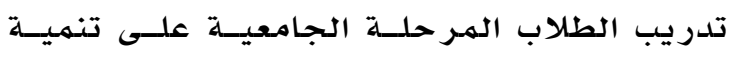

الحسابي Arithmetic Aptitude و الاستعداد الرياضي Mathematics Aptitude واليسي على إجراء العمليات الحسابية Ary Arithmetic Operations الاستدلالية من أولى القدرات العقلية من حيث

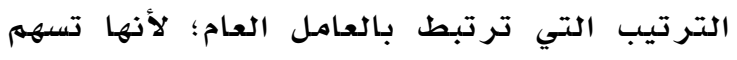

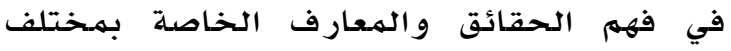

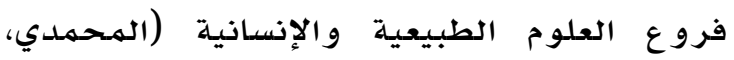

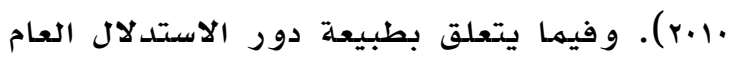

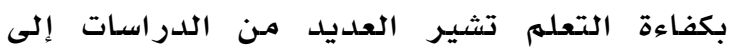

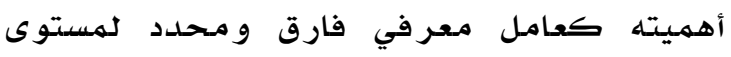
كفاءة التعلم بين طلاب التخصصات العلمية

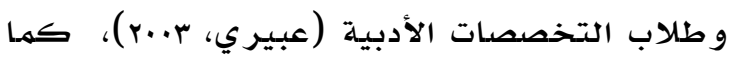

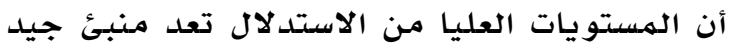

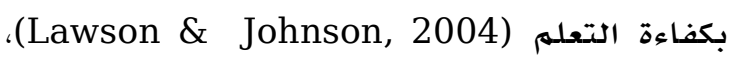

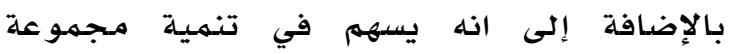

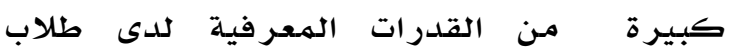

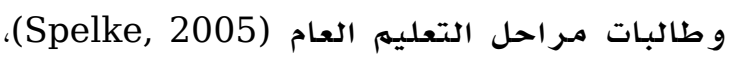

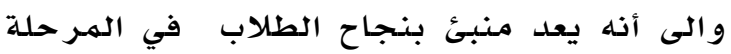

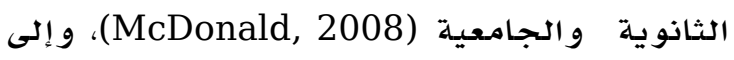

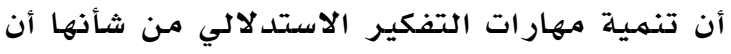

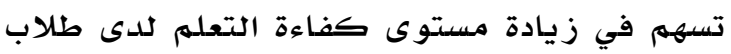

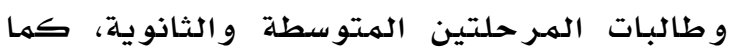

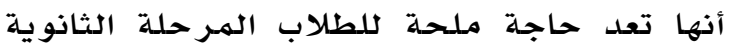

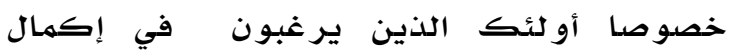

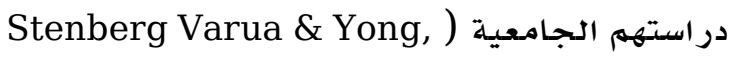

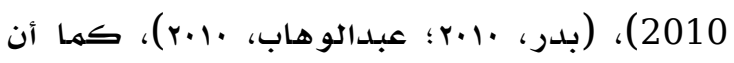

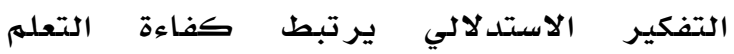

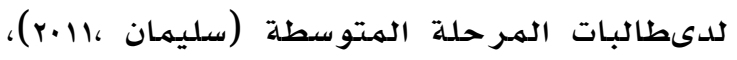

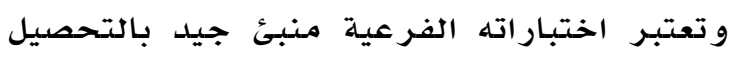

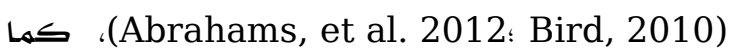
أن الاستدلال يعد سببا مباشرا في التفاوت في

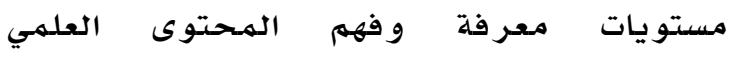
للمقرر ات الدر اسية لدى الطلاب.

و يعد مفهوم ما وراء الذاكرة Meta- memory

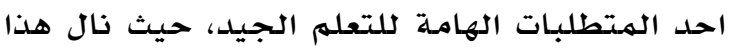

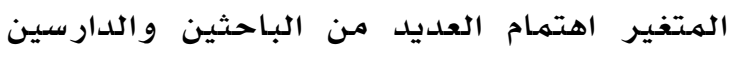

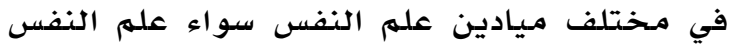

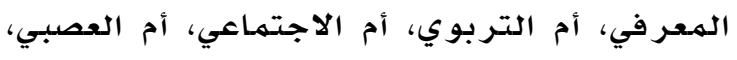

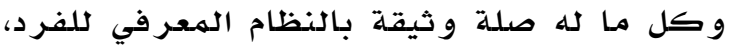


موضوعات، و يقومون بإدمـاج الخبرة والتتدرب عليها مـن اجل استدعائها في صورة تناسب مواقف

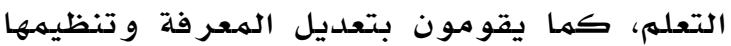
من اجل تحقيق النتائج المتوقعة، وتعد المروونة

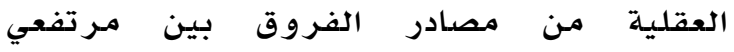

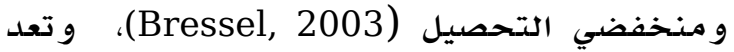
من ابرز المشكلات التي يعاني منها الطلاب

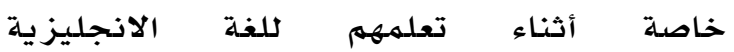

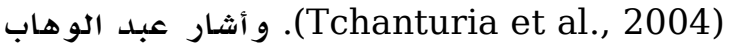
(r.11) (إلى أن الهرونة العقلية وفقا لهنظور McNulty, et al.

Adaptive Flexibility الهرونة التكيفية ويقصد بها قدرة الفرد على تغيير الوجهة الذهنيـة التي ينظر من خلالها إلى حل

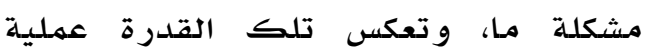
الجمود الذهني، كها تشير إلى قدرة الفرد

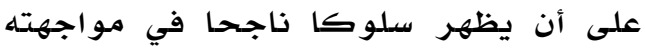
للمشكلة، و بذلك فإنه يتكيف مـع الهشكلة الجديدة بأوضاعها المتعددة، ومـع الصور الهـتلفة التي تظهر عليها.

• المروونة التلقائية Flexibility

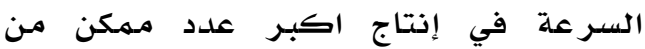
الأفكار المتنوعة تجاه موقف معين.

و تشير بعض الدراسات والبحوث النفسية و التربوية إلى أهمية متغير الهرونة العقلية كعامل يسهم في تحسين كفاءة التعلهم، فهي تر تبط بارتفاع مستوى كفاءة التعلهم في مختلف

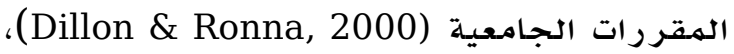
كما أنها ترتبط باستخدام الاستر اتيجيات المعر فية تسهم في تحسين مستوى كفاءة التعلهم

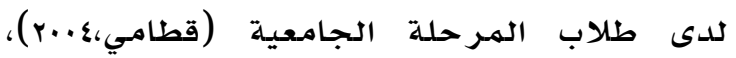
وترتبط بكفاءة التعلهم وحل الهشكلات للدى

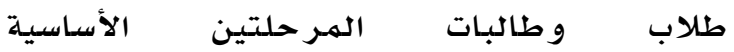
و الثانوية (Eagle, 2004)، وترتبط بالتحصيل الدراسي و أساليب التعلهم، و تعد منبئ جيد بكفاءة التعلهم في مقرر الرياضيات لدى طلاب المرحلة

الهتو سطة (Q Bing, 2011).
مكونات ما وراء الذاكرة لديهم تسهم في تعزيز كفاءة الاستدعاء مسـن الـذاطرة قصــيرة المــدى و من تحســين مهـارات الفهـهم والقـر اءة لــديهم (Schwartz \& Efklides, 2012)

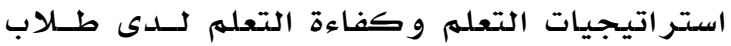

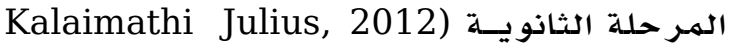
. $(\&$

و في المقابل يرجـ اهتمام الدراسة الحالية

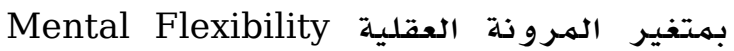

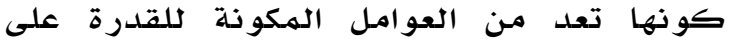

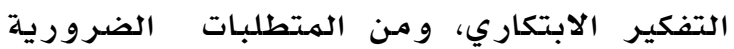

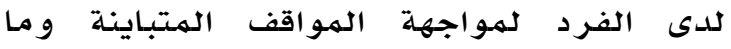
يترتب عليها من متغيرات، ولارتباطها الكبير بمستوى كفاءة التعلهم. ويشير عبد الوهاب

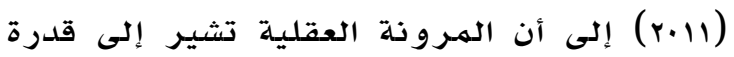

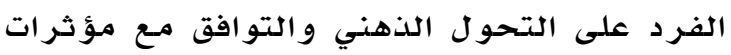
البيئة المتغيرة، والقدرة على إنتاج حلول بلديلة

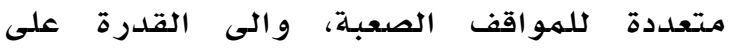

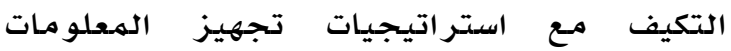
لهواجهة ظروف جديدة وغير متوقعة. و وتشير

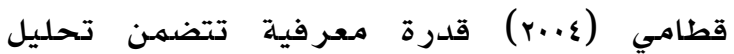
عمليات التواصل الذهني والمعرفي بين الهعلم و المتعلهم ،بالإضافة إلى أنها تعبر عن مدى الوعي

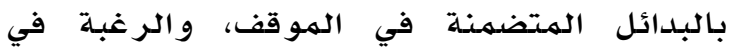
تكييف الهموقف، فالطلاب الذين يتصفون بامتلاك مرونة عقلية عالية هم الذين يقومون بتوليد ذاتي للمعرفة مـن خلال التعديل في المعرفة التي التي

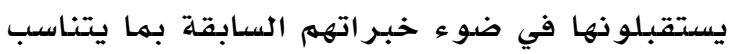
مـع الموقف، مها يساعدهم على التحرك كت الذهني

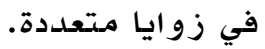

و على الصعيد التربوي يمكن تلمس أهمية هذا Torry الهتغير فيما أشارت إليه دراسـة (2003)

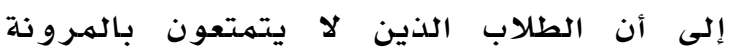

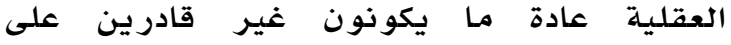

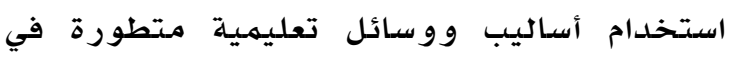
التعلهم مـما ينعكس سلبـا على تحصيلهم الدر اسي

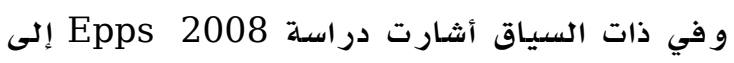

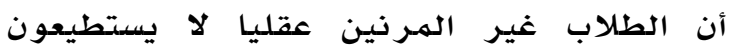
استخدام الحاسب الآلي في التعلهم، كها أنهم

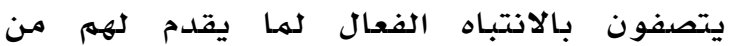


البصرية ومدى الذاكرة) وقدرات الاستدلال ماتل

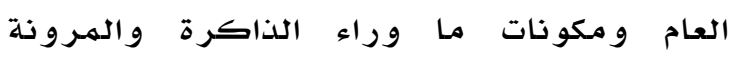

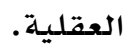

أهميلة الدراسـة: تبرز أهمية الدراسـة الحالية من خلال: اهله

ا. تركيزها على بعض المتغير ات المعر فيسة

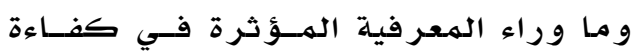

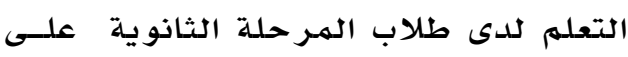

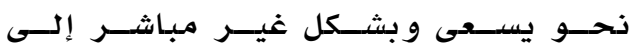

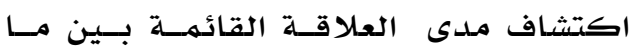
يتعلمهـ الطالب في المدررسة الثانوية. r. الاستفادة من نتــائج الدراســة فـي اقتــراح

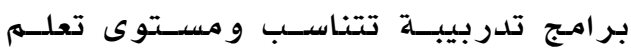

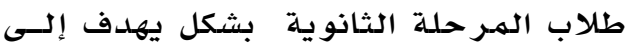

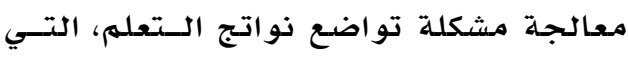

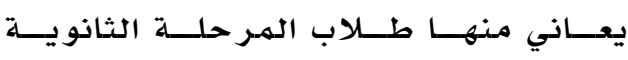

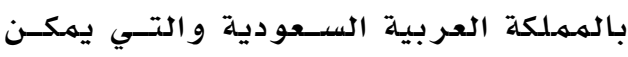
تلمسس آثارهـا فــي نتــائج اختبــار قيـاس

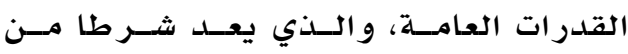

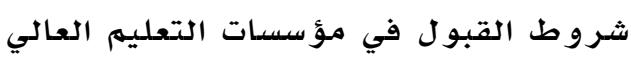

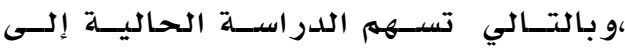
محاولة تحقيق هدف جودة عمليات التعلهم

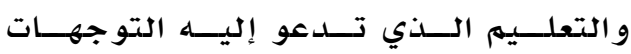

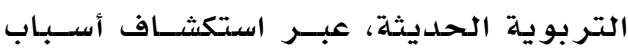

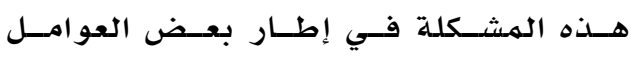

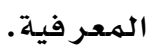
r. أذها تعتبر الدراسة الأولى من نوعهـا فـي

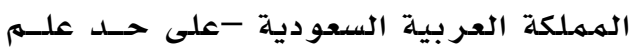
الباحث - التي تتناول هذه المتغير ات فـي الهي

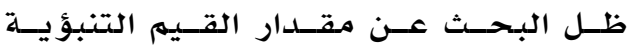
والفروق بين متفاوتي بين كفاءة الـتعلم لدى طلاب المر حلة الثانوية.

\section{مصطلحات الدراسة}

الــذاكرة البصــرية Visual Memory القــدرة علسى تـذكر ترتيـب أثـكال و موضـعها

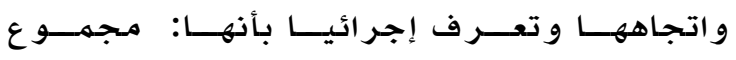

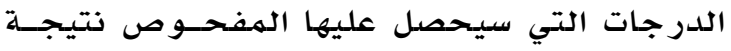

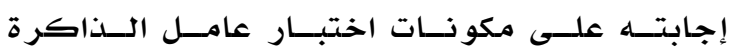

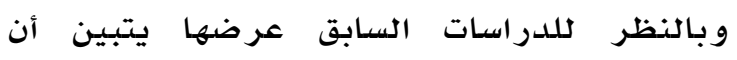

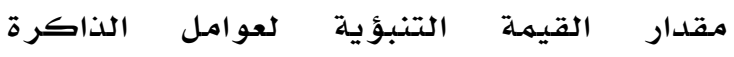

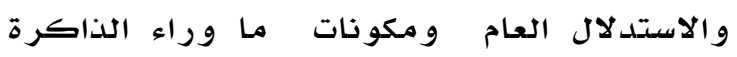

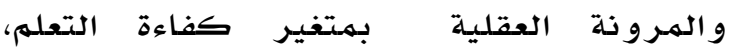
و كذلك طبيعة الفروق بين متفاوتي كفاءة

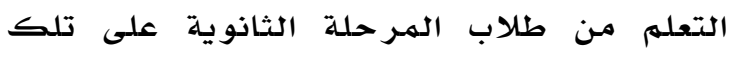

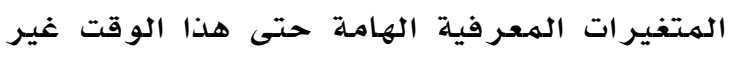

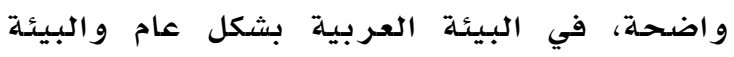
المحلية بالمملكة العربية السعودية بشكل خاص.

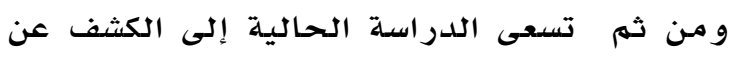

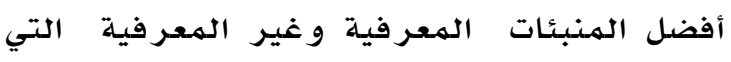
تتنـاو لها الدراسلة الحالية، والتي يمكن من خلادلها

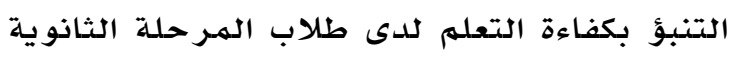

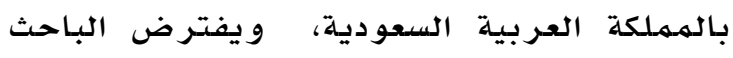

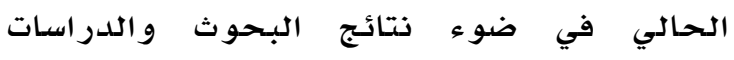
السابقة التي أكدت على وجود علاقات إرتباطية

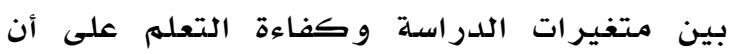

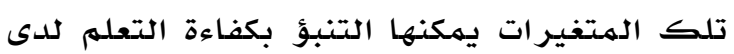
طلاب المـرحلة الثانوية بشكل عام.

مشكلة الدراسة

تتحدد مشكلة الدراسة الحالية في التسـاؤلين الآتيين: السؤال الأول: هل توجد فروق بين متفاوتي

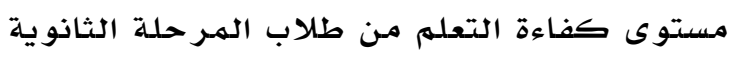
على مقاييس الذاكرة البصرية ومدى ملدى الذاكرة

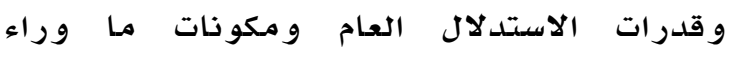
الذاكرة و الهـرو نة العقلية؟؟.

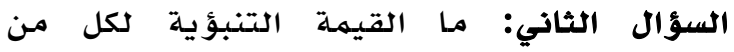

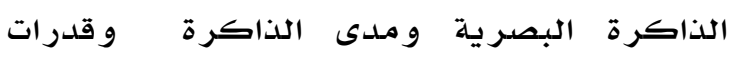

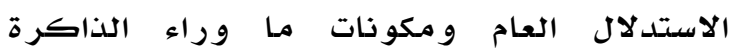

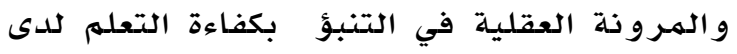

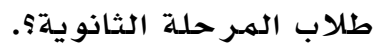

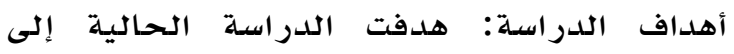
الكشف عن طبيعة الفروق بين متفاوتي كفاءة

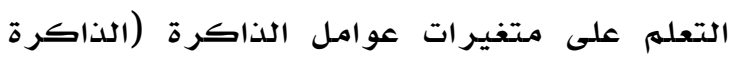

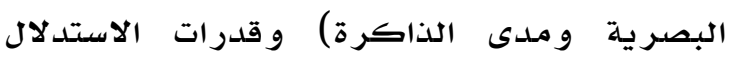

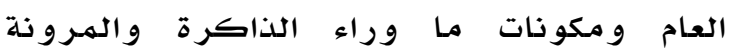
العقلية، بالإضافة إلى الكشف عن أفضل المنبئيات

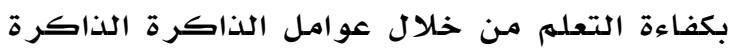




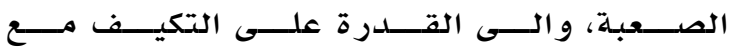

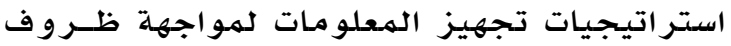
جلديدة وغيـر متوقعسة وتعـر فيات إجـر ائيـا بأنهـا:

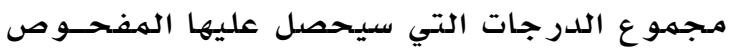
نتيجة إجابته على مقيـاس المروونة العقلية إعــداد

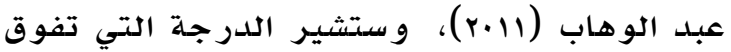
المتوسط و التي سيحصل عليها المفحــوص إلـى

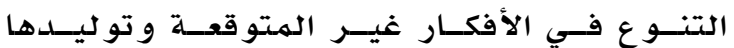

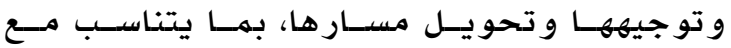
المثير أو متطلبـات المـوقف مـع سلاســة التفكيـر و عدم الجمود الفكري.

كفاءة التعلم Learning efficiency: هي إتقان المتعلهم للمعلو مـات و للهمهارات التي حصـل عليهـا مـن خلال عملية التعلـيم الثــانوي والتــي تقــدر

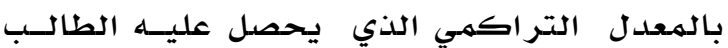
في نهاية العام الدراسي فـي مختلـف المقــررات

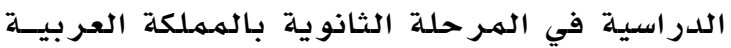

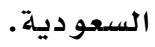

\section{الطريقة و الإجر اءات}

قام الباحث باستخدام المنهج الوصـفي لمنـاسـبته

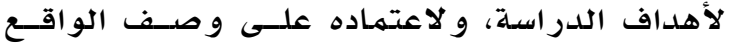

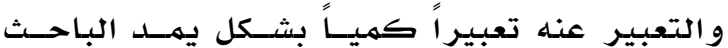

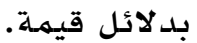
مينة الدراسة

تكونت من Y.r طالب مـهـن يـدرسـون بالهـر حلــة

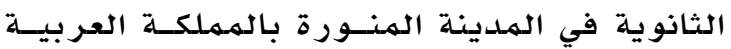

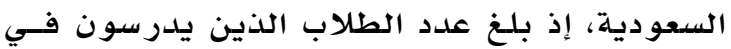

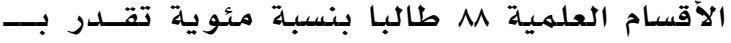

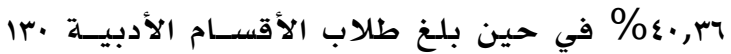

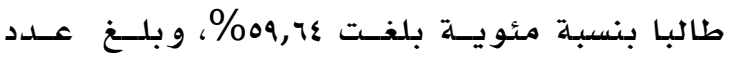

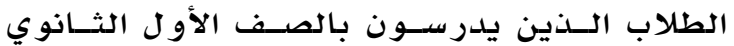
طالبا بنسبة مئوية بلغتعاب,\%ror عدد الطلاب الذين يدرسـون فــي الصــف الثـاني

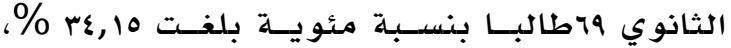

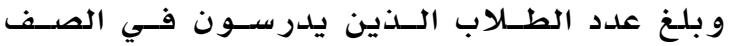

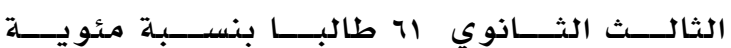

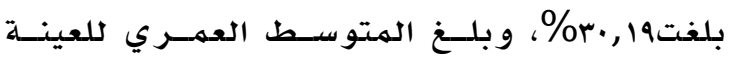
الكليــا IV سـنـة و ول شــهور بـانحر اف معيـاري
البصـر يـة تعريسب و إعـداد الشـرقاوي و القفــاص

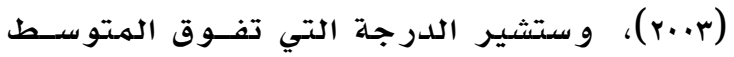
و التي سيحصل عليها المفحوص ص إلى قدرته علـى تذكر مجموعة من الأشـكال ومواقعهــا بالنسـبـة النهية لبعضها، أو على الخر ائط.

ملدى الذاكرة Memory Span: هي القدرة على الاســتدعاء الفـوري لعسـدد مــن العناصــر غيــر

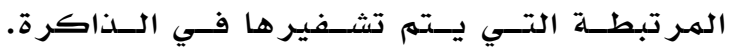

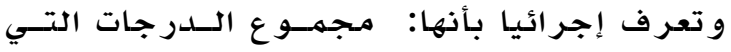

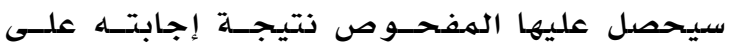
مكونات اختبــار مــدى الــذاكرة تعريسب و إعــداد

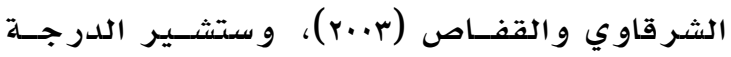
التـي تفـوق المتوسطـ و والتـي سيحصـل عليهـا المفحوص ص إلى قدرتـهـ علــى الاســتدعاء الفــوري لسلسلة من الأعداد والحروف فير الدور المرتبطة الاسـتدلال العـام Reasoning General: هـي معيس عمليسـة عقليسة منطقيـة تتضسمن مجمموعسة مسن الههارات التي يتم فيها الاستفادة من الهعلومهـات

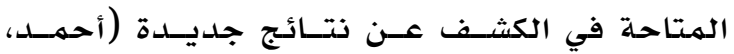

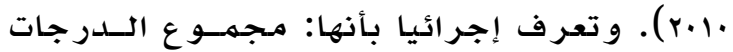
التي سيحصل عليها المفحوص نتيجة إجابته على إسى

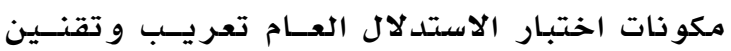

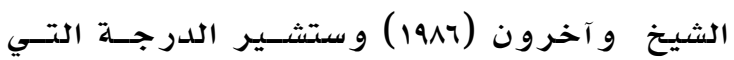
تفوق المتوسط والتي سيحصل عليها المفحـوص إلى امتاكلاكه للقدرة الاستدلالية.

Meta memory مكونـات مــاء وراء الـذاكرة ذأس :Components ذاكرته، ووظيفـة الــاكرة اليوميـهة، ومــدى

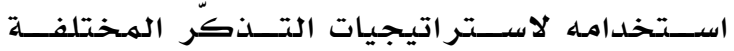

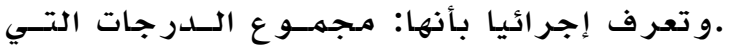

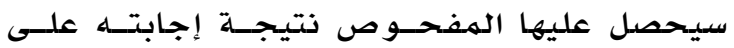

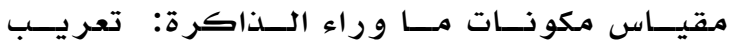

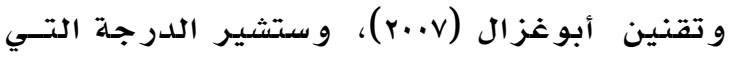

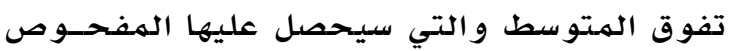
إلى ارتفاع مدىى رضا الهفحــوص عــن ذاكر تــه،

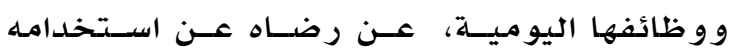

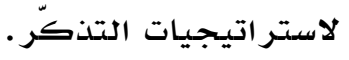

المرونة العقليـة Mental Flexibility: قـــدرة الفرد على إنتاج حلول بلديلــة متعـددة للهوواقـف 


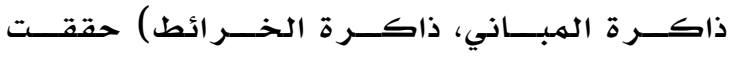

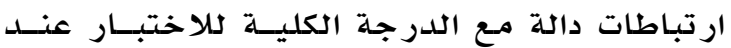

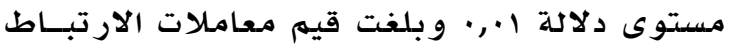

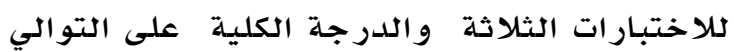
$\cdot, 09\{\lfloor\cdot, 01 \cdot\lfloor\cdot$, TrY

ثبات الاختبار

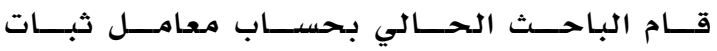
الاختبارات الثلاثة ذاكرة الشكل، ذاكرة المباني، ذاكرة الخــر ائط التــي تقـيس عامـل الــذاكرة

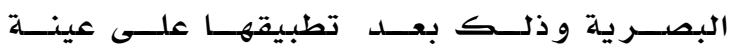

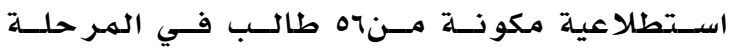

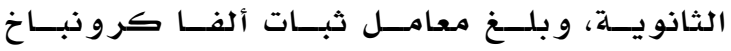

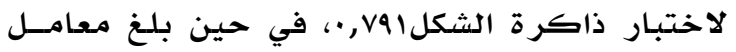

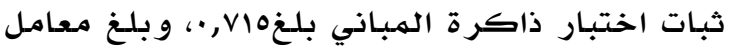

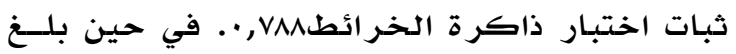
معامل ثبـات اختبــار عامسل الـذاكرة البصــرية ككل|+1,،وووفقا لمعاملات صدق وثبـات اختبـار عامل الذاكرة البصرية يطمئن الباحث لاستخدام هذا الاختبار في الدراسـة الحالية.

اختبار عامـل مـــى الــذاكرة: تعريـب وإعـداد الشر قاوي و القفاص (r..r)

قام الشرقاوي و القفاص (r..r) بتعـريسب و إعـــاد هذا الاختبار الذي يعتمدد على الاستدعاء الفـوري

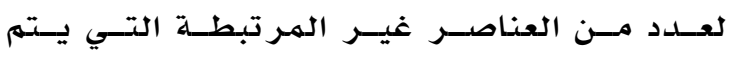
تشفير ها في الذاكرة، والاختبـارات التــي تقـيس

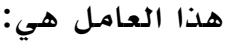

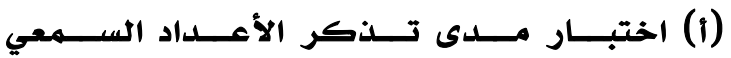
Auditory Number Span Test

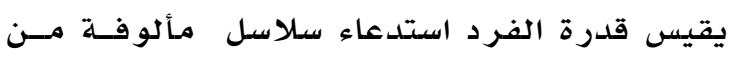

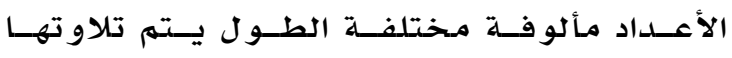
بسر عة كل ثانية.

(ب) اختبار مدى تذكر الأعداد البصري Visual Number Span Test

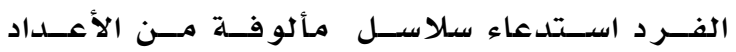
مختلفة الطول يتمم على كروت كبيرة.

(ج) اختبــار مــدى تـذكر الحــروف السـمعي Auditory Letter Number Span Test اختبار يقيس قدرة الفرد اسـتدعاء سـلاسـل مـن
مقدار 1,V00. و ووفقا للهمعدل التر اكهي تم تصنيف أفر اد عينـة الدراســة إلـى ثلاثــة مســتويات مــن كفاءة التعلهم و هي: منخفض، متوسط، مر تفع. أدوات الدراسة

اختبار عامل الذاكرة البصرية: تعريـبـ

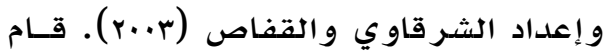

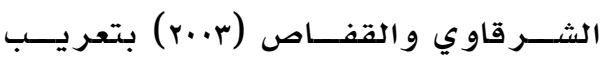

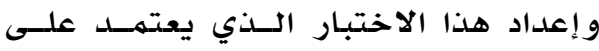
تذكر ترتيب أشكال و موضعها و اتجاهها،

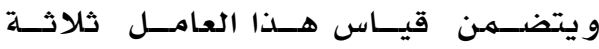
اختبارات فرعية هي:

Shape Memory اختبار ذاكرة الشكل

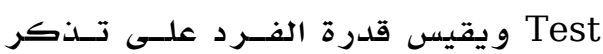

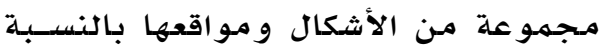

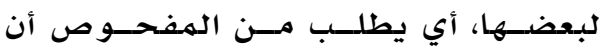
يتعرف على تلك الأشكال غير المنتظمهة التي ر آها في نفس الاتجاه.

Building اختبــار ذاكــرة المبـانيـي Memory Test على تذكر موقع الأشياء علـى خريطــة

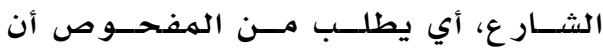
يعين عدد من الشوارع و الأبنية و مكونات أخرى على خريطة درست من قبل.

Map Memory اختبار ذاكرة الخرائط

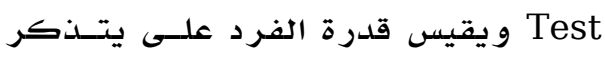

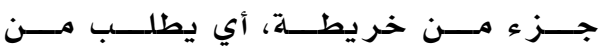
الهفحوص التعرف على تلك الخـــر ائط التي قدمت من قبل على صفحة الدمر الدر اسلة.

الخصائص السيكومترية للاختبار فـي الدراسـة

الدحالية

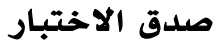

قام الباحث الحالي بالتحقق من صدسدق اختبـار عامل الذاكرة البصرية عن طريق حساب الاتساق

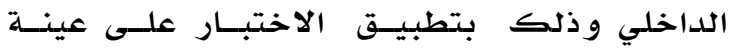

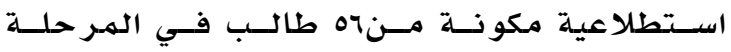
الثانوية، و بحسـاب معامل الارتباط بين درجة كل

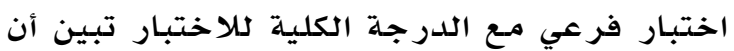

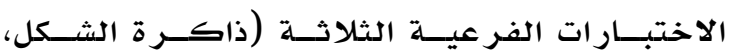


و تقنينه على البيئة العربية، و قام عبيـري (r..r) بتقنين الاختبـار على البيئة السعودية. و يستـتهدف

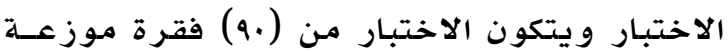
على ثلاثة اختبار ات هي:

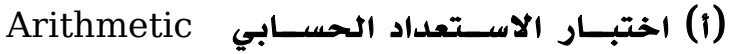
Aptitude الحسـابي، وتتطلب الإجابة على تلــك الفقـر ات بأن تحل بعض المسائل الحسابية، وتحسب درجة إنة الهفحسـوص مسـن خــلال حســاب عــدد الإجابـات الصحيحة مـحصو مـا منها عدد الإجابات الخاطئة. (ب) اختبـار الاسـتعداد الرياضـي Mathematics : Aptitude الر ياضي، وتتطلب الإجابة على تلك الفقر ات بأن تحل بعض المســائل الحسـابية، وتحسـب درجــة

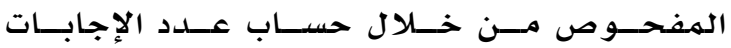
الصحيحة مخحصو ما منها عدد الإجابات الخاطئة.

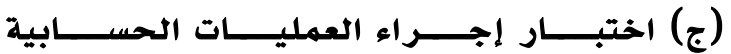
:Necessary Arithmetic Operations و يتكون من ·r فقرة تقيس القدرة على تحديسد العمليات الحسابية التي يمكن استخدامها في حسل الهسألة الحسابية، وتتطلب الإجابـة علـى تلــك الفقـر ات بـأن تحسل بعـض المســائل الحســابية. و تكـون الدرجــة الكليـة الهـركبـة هــي حاصـل

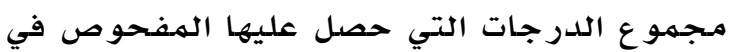
الاختبارات الثلاثة وهي •ه درجة.

الخصائص السيكومترية كلاختبار فـي الدراســة الدحاثية

\section{صدق الاختبار}

قام الباحث الحالي بالتحقق من صدسدق اختبـار الاستدلال العام عن طريق حساب الاتساق الداخلي و ذلك بتطبيق الاختبار على عينــة اسـتطلاعية مكونــة مــن با طالـبب فـي الهـر حلــة الثانويـة، و بحسـاب معامل الارتباط بين درجة كل مبل اختبـار فر عـي مــع الدرجــة الكليـة للاختبـار تبـين أن

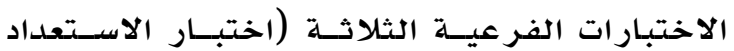

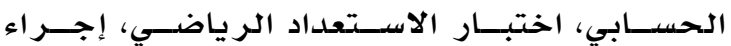

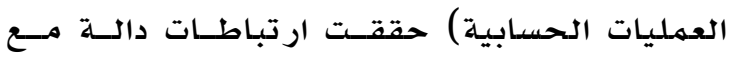
الدرجة الكلية للاختبار عند مسـتوى دلادسة ا.,.
الحرووف مألوفة من الحروف مختلفة الطول يتم تلاوتها بسر عة كل ثانية.

الخصائص السيكومترية للاختبار في الدراســة

الحمالية

صدق الاختبار

قام الباحث في الدرراســة الحـاليسة بـالتحقق مــن

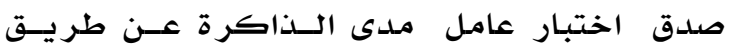
حساب الاتساق الداخلي وذلك بتطبيق الاختبار

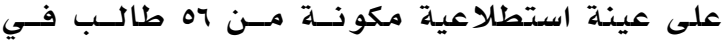

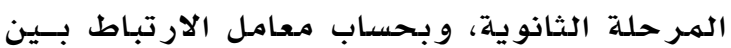
درجلة كل اختبـار فرعسي مـع الدرجــة الكليـة

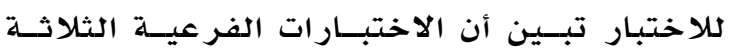

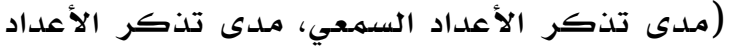

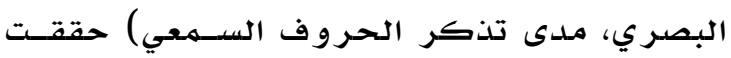

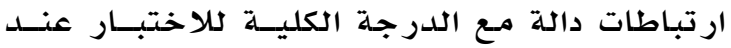
مستوى دلالة ا+, ب و بلغت قيم معاملات الارتبـاط

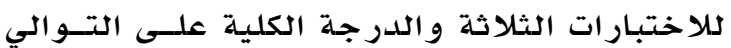
$\cdot, \varepsilon \vee 0 \leq \cdot, 0 \wedge r \leq \cdot, \varepsilon \cdot 1$

ثبات الاختبار

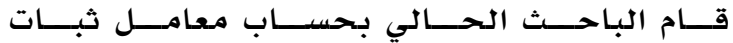
الاختبارات الثلاثة (مدى تذكر الأعداد السـهعي،

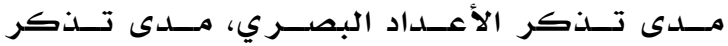

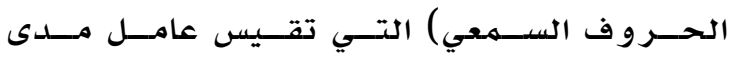

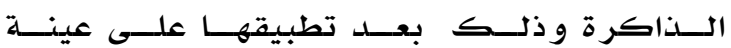
استطلاعية مكونـة مــن هـ طاسب فــي الهـر حلــة

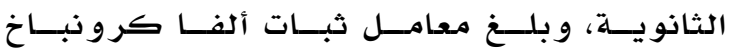
لاختبار مدى تذكر الأعداد السـمعي: هrV, י، فـي حين بلغن معامل ثبات اختبـار مدى تذكر الذكر الأعـداد

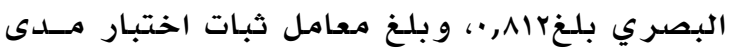

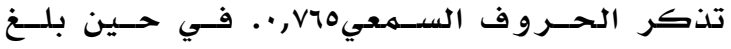

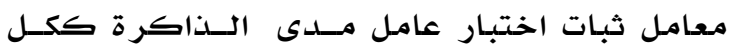

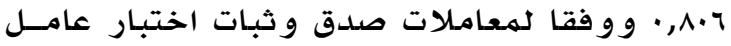
مدى الذاكرة يطمسئن الباحسث لاسـتخدام هـــا الاختبار في الدراسـة الحالية.

اختبار الاستدلال العام: تعريب وتقنـين الشـيخ و آخرون (1917)

قــام اكســترو م و آخــرون (ساول) بإعــداد هــــا

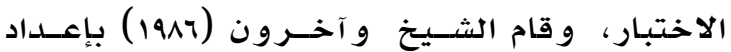




$$
\begin{aligned}
& \text { و يــتم تصدسحيح المقيـاس وفــق التــدرج } \\
& \text { الرباعي (rrrr،r. }
\end{aligned}
$$

الخصائص السيكومترية للمقياس في الدراسـة

الحالية

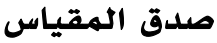

قام الحربي(r/r) بالتحقق من صــدق المقيـاس باستخدام طريقة حسـاب الاتسـاق الـداخلي بـين

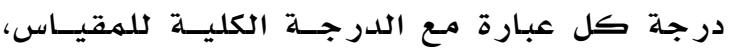
و ذلك بعد تطبيقه على عينة استطلاعية مكونسة

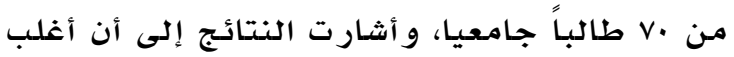
عبارات مقياس مكونات مـا وراء الذاكرة حققـت

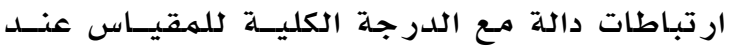

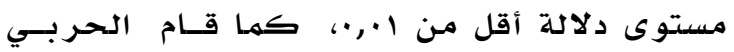

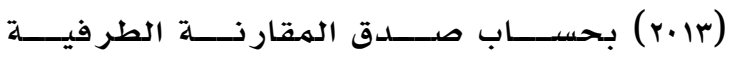

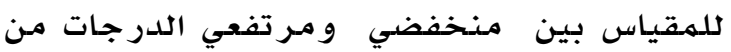
أفر اد العينـة الاستطلاعية وتبين وجود فروق دالة

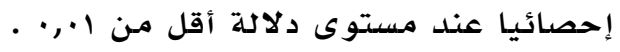

و نظـــر ا لاخـتلاف الخصــائص العمـر يسـة لعينــة الدراسـة الحالية قام الباحث الحالي بإعادة حساب

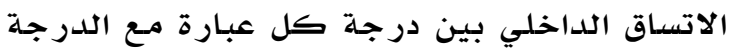

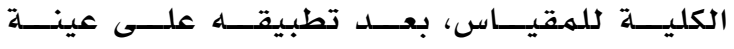

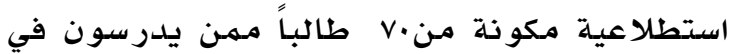

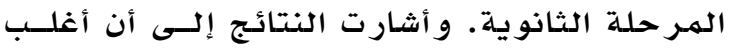

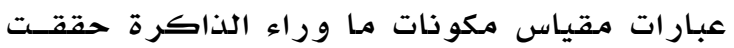

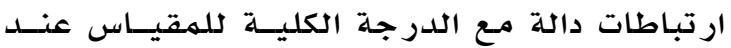
مستوى دلالة ا..,•إذ تراوحت معامـلات الارتبـاط

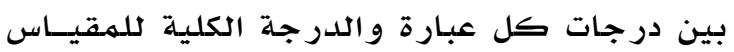

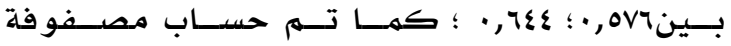

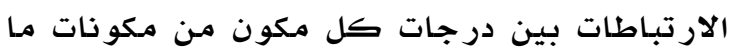

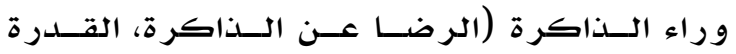

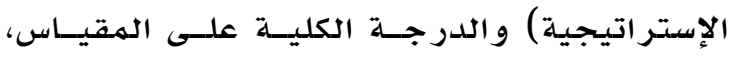

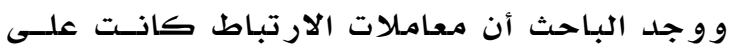

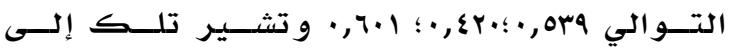

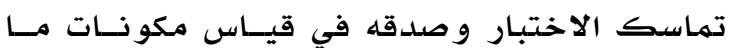
وراء الذاكرة.

\section{ثبات المقياس}

قام الحربي(r/r.r) بحسـاب معامل الارتبـاط بـين

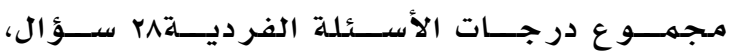

و بلغت قيم معامـلات الارتباط بـين الاختبـارات الثلاثة والدرجة الكليـة للاختبــار علـى التــوالي

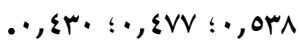

ثبات الاختبار

قــام الباحسـث الحـــالي بحســـاب معامــل ثبـــات

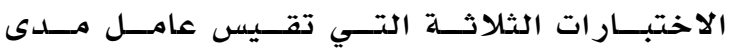
السذاكرة وذلــك بعـد تطبيقهـا علـى عينــة

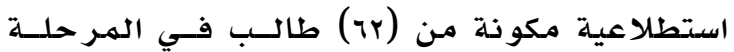
الثانويلة، و بلـغ معامل ثبات ألفا كرو نباخ لاختبـار

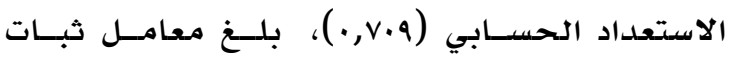

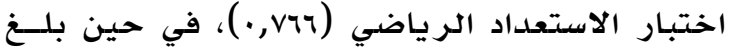
معامل ألفا كرونباخ لاختبـار إجــراء العمليـات

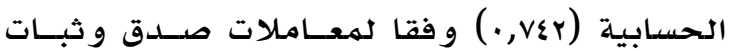

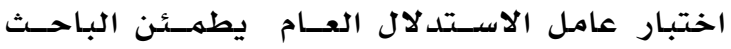
لاستخدام هذا الاختبار في الدراسـة الحالية. ع- مقياس مكونات مـا وراء الذاكرة: تعريب

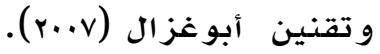

Troyer \& Rich (2002) قـام ترويـر وريــتش

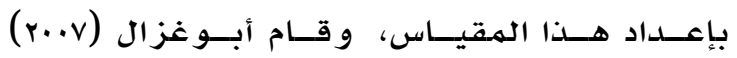

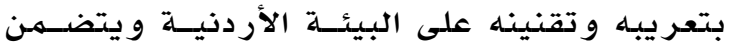

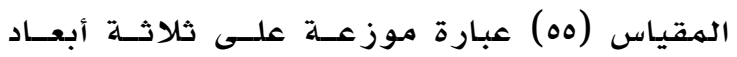

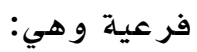

ا. الرضا عن الذاكرة: Satisfaction with Memory لتقدير مدى رضا الفرد عن قدرة الذاكرة

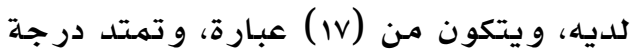

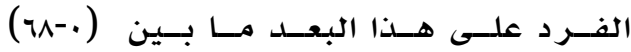

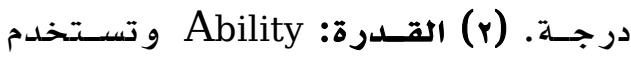
عبارات هذا البعد لتقدير وظيفة الـذاكرة

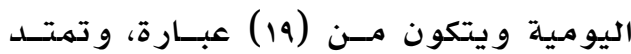
درجة الفرد على هذا البعد ما بين (. - (vi) درجهة. r. (r) الإسـتر اتيجية: Strategy و تسـتخدم عبارات هذا البعد لتقــدير مــدى اسـتخدلمام

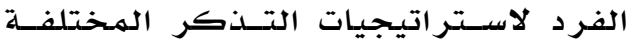

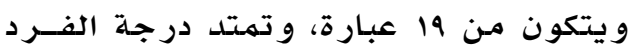

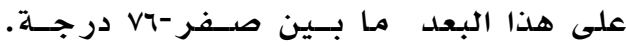




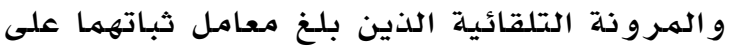

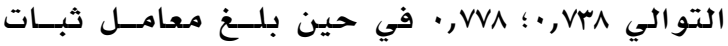

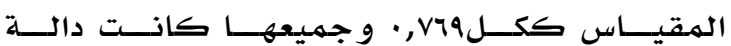
إحصائيا.

الخصائص السيكومترية للمقياس في الدراسـة الححالية:

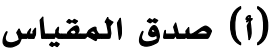

قام الباحث الحالي بالتحقق مسن صــدق مقيـاس الهمرونــة العقليــة عـن طريـق حســـاب الاتســاق

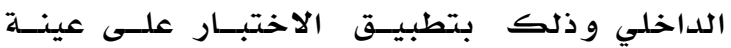

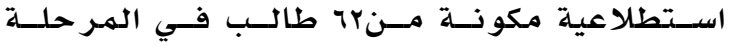

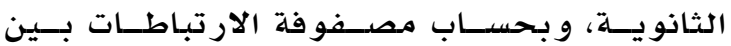
البعدين المكونين للمقياس بلغ معامسل الارتبـاط

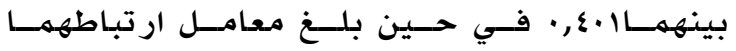

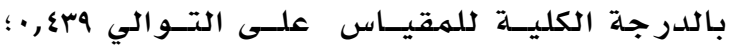
01V, و جمهيعها كانت دالة إحصائيا عند مسـتوى $\cdot, \cdot 0$

\section{(ب) بات المقياس}

قام البـاحث الحسالي بإيجاد معامل ثبــات مقيـاس المـرونة العقلية على عينة استطلاعية مكونة من

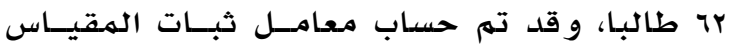
باسـتخدام طريقــة ألفــا كرو نبــاخ فوجــد أنسـه يسـاوي سM, • مسما يطمئن الباحث لهـذا الهقيـاس من حيث استخحلدامه في الدراسلة الحالية.

\section{نتائج اللدراسة ومناقشتها}

نص السؤال الأول على: هل توجد فروق بين متفاوتي مستوى كفاءة التعلم ع من طلاب

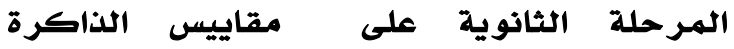

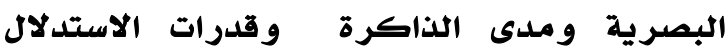
العام ومكونات ما وراء الذاكرة والمرونة العقلية \& و للإجابة على هذا التساؤل تم استخدام

تحليل التباين الأحادي One-Way ANOVA.
و مجمهـوع درجـات الأســـلة الزوجيـة rV سـؤال، و الهكونة لهقياس ما ور اء الذاكرة و بلـغ معامسل

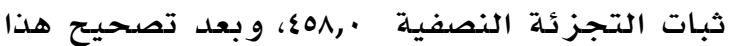

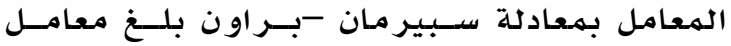

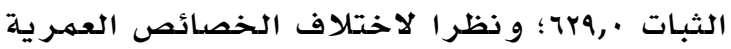
لعينـــة الدراســة الحـاليسة قـام الباحسـث الحــالي

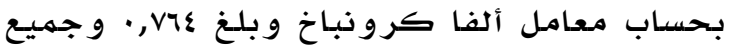

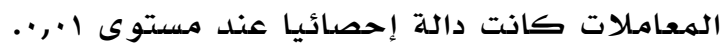
و نظـــر الاخــتلاف الخصــائص العمبريـــة لعينــة

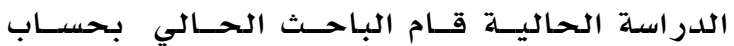
معامل الارتبـاط بـين مـجمـوع درجــات الأســئلة

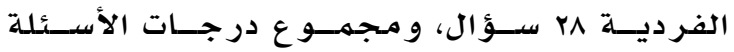
الزوجية rV سؤال، و المكونــة لمقيـاس مـأ وراء

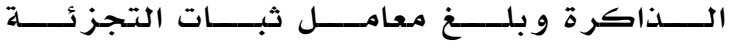

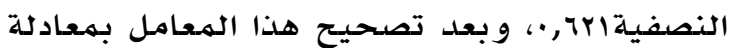
سبير مان -بر اون بلغن معامل الثبات •rآ, • ثم قـام

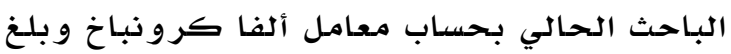

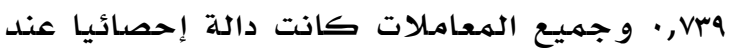
مستوى ا+,•، الأمـر الذي يدل على درجة مقبولة من الثبات تفي بمتطلبات تطبيق مقياس مكونـات ما وراء الذاكرة على عينة الدراسة الفعلية. مقياس المروونـة العقليــة: إعـــاد عبـــ الوهــاب $(r+11)$

قام عبد الوهاب (11) بإعداد هذا الهقياس بهدف قياس مدى تغير الوجهة الذهنية أو التنـوع فـي

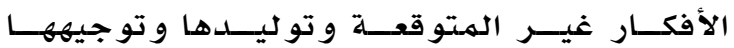

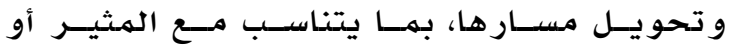

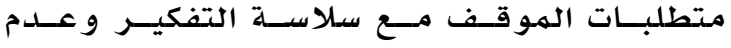
الجمهود الفكري. و يتكون المقياس مسن ·rعبـارة

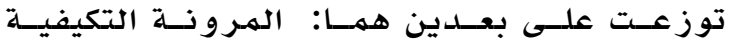
و تقيسها العبارات مـن ا-10، و البعد الثاني المرورنة

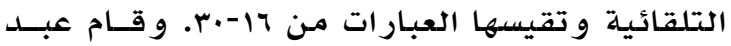

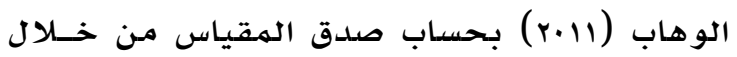

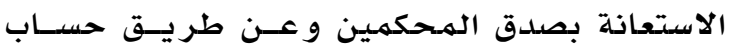
كاب، و كانت جميع الهعاملات دالة إحصائيا عند

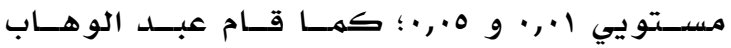

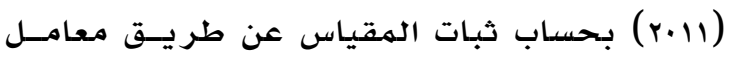

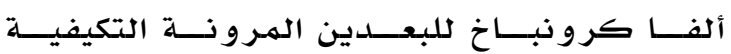


جدول 1 (أورة

تحليل التباين لمعرفة دلالة الفروق بين متفاوتي مستوى كفاءة التعلم على مقاييس الذاكرة البصرية ومدى الذاكرة وقدرات الاستدلال العام ومكونات ما وراء الذاكرة و المرونة العقلية

\begin{tabular}{|c|c|c|c|c|c|}
\hline الدالة & ف & متوسط مجموع المربعات & $\tau \cdot د$ & مصدر التباين & المتغيرات \\
\hline \multirow[t]{2}{*}{$\cdot, \cdot 1$} & q,re & $r \cdot, 0 \leqslant 7$ & r & بين المجموعات & عامل الذاكرة البصرية \\
\hline & & r,ґی. & 199 & داخل المجموعات & \\
\hline \multirow[t]{2}{*}{$\cdot, \cdot 1$} & $V, \varepsilon r$ & $\leq \pi, 1 \pi \mid$ & r & بين المجموعات & عامل مدى الذاكرة \\
\hline & & $7, \Upsilon \wedge 9$ & 199 & داخل المجموعات & \\
\hline \multirow[t]{2}{*}{$\cdot, \cdot 1$} & אד, & 97,070 & r & بين المجموعات & الاستعداد الحسابي \\
\hline & & $v, 707$ & 199 & داخل المجموعات & \\
\hline \multirow[t]{2}{*}{$\cdot,+1$} & $r \leq, 1$ & r^^, 9०V & r & بين المجموعات & الاستعداد الرياضي \\
\hline & & $11,99$. & 199 & داخل المجموعات & \\
\hline \multirow[t]{2}{*}{$\cdot,+1$} & $0,1 r$ & IrT,VT. & r & بين المجموعات & العمليات الحسابية \\
\hline & & rr,qrV & 199 & داخل المجموعات & \\
\hline \multirow[t]{2}{*}{ 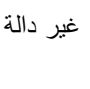 } & $1,9 r$ & $10,7 \cdot 1$ & r & بين المجموعات & تقدير الرضا عن الذاكرة \\
\hline & & $\Lambda, 1 \pi$ & 199 & داخل المجموعات & \\
\hline \multirow[t]{2}{*}{$\cdot,+1$} & $V, T \leq$ & v^, ro. & r & بين المجموعات & تقدير وظيفة الذاكرة \\
\hline & & $1 \cdot, r \circ \Lambda$ & 199 & داخل المجموعات & \\
\hline \multirow[t]{2}{*}{$\cdot, \cdot 1$} & $r \leq, 9 \leq$ & $7 \cdot V \leqslant, 0 \wedge 1$ & r & بين المجموعات & تقدير استخدام استراتيجيات التذكر \\
\hline & & $r \leq r, O \wedge V$ & 199 & داخل المجموعات & \\
\hline \multirow[t]{2}{*}{$\cdot, \cdot 1$} & $r \wedge, \vee \vee$ & $\varepsilon 00, \pi r r$ & r & بين المجموعات & المرونة العقلية \\
\hline & & $11, V \vee \varepsilon$ & 199 & داخل المجموعات & \\
\hline
\end{tabular}

المقارنات البعدية بطريقة شيفيه Scheffe بين متفاوتي مستوى كفاءة التعلم على مقاييس الذاكرة البصرية ومدى الذاكرة وقدرات الاستتلال العام ومكونات ما وراء الذاكرة و المرونة العقلية

\begin{tabular}{|c|c|c|c|c|}
\hline \multicolumn{2}{|c|}{ فروق المتوسطات ودلالتها } & \multirow[t]{2}{*}{ المتوسطات } & \multirow[t]{2}{*}{ المجموعات } & \multirow[t]{2}{*}{ المتغيرات } \\
\hline منخفضي الكفاءة & مرتفعي الكفاءة & & & \\
\hline & & $r \leqslant, \varepsilon$. & منخفضي الكفاءة & عامل الذاكرة البصرية \\
\hline$\cdot, \wedge$. & $\cdot, 70$ & ro, r & منوسطي الكفاءة & \\
\hline \multirow{2}{*}{$* 1, \leq 7$} & & ro,NT & مرتفعي الكفاءة & \\
\hline & & TY,YT & منخفضي الكفاءة & عامل مدى الذاكرة \\
\hline$* * *, 1$ & $\cdot, \Gamma \varepsilon$ & די, & متوسطي الكفاءة & \\
\hline \multirow[t]{2}{*}{$* * 0, \cdot 9$} & & $r o, v$. & مرتفعي الكفاءة & \\
\hline & & $r \cdot, r)$ & منخفضي الكفاءة & الاستعداد الحسابي \\
\hline$\cdot, 91$ & $* * r, \vee$ & ri,or & متوسطي الكفاءة & \\
\hline \multirow{2}{*}{ ** } & & $r \leqslant, r r$ & مرتفعي الكفاءة & \\
\hline & & $\leqslant \vee, १ १$ & منخفضي الكفاءة & الاستعداد الرياضي \\
\hline $1, r \varepsilon$ & $* * r, r$ & $\varepsilon q, r r$ & منوسطي الكفاءة & \\
\hline \multirow[t]{2}{*}{$* * r, \Upsilon \leq$} & & תוד & مرتفعي الكفاءة & \\
\hline & & $r r, \wedge \varepsilon$ & منخفضي الكفاءة & إجراء العمليات الحسابية \\
\hline$* 1,0 \leq$ & $\cdot, r q$ & ro, r & منوسطي الكفاءة & \\
\hline \multirow[t]{2}{*}{$* * 1,94$} & & ro, rv & مرتفعي الكفاءة & \\
\hline & & $\varepsilon \varepsilon, r r$ & منخفضي الكفاءة & تقدير وظيفة الذاكرة \\
\hline$* * 1, \lambda r$ & $* * \vee, \vee 1$ & $\leq 7, .0$ & متوسطي الكفاءة & \\
\hline \multirow[t]{2}{*}{$* * 9$, or } & & or,vi & مرتفعي الكفاءة & \\
\hline & & ro,17 & منخفضي الكفاءة & تقدير استخدام استراتيجيات التذكر \\
\hline$* * \leq, 10$ & $* * r, r r$ & $r q, r)^{\prime}$ & متوسطي الكفاءة & \\
\hline \multirow[t]{2}{*}{$* * V, \Sigma V$} & & & مرتفعي الكفاءة & \\
\hline & & $r v, r$, & منخفضي الكفاءة & المرونة العقلية \\
\hline$* * 1,7 \leq$ & I,rr & $r \wedge, 90$ & منوسطي الكفاءة & \\
\hline$* * r, 97$ & & $r \cdot, r v$ & مرتفعي الكفاءة & \\
\hline
\end{tabular}


البصرية من دور هام في كفاءة التعلم لدى

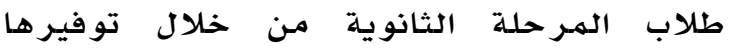
للمتعلم سياقات معرفية بهرية بهكن على

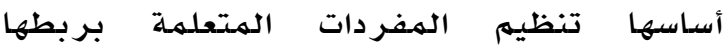
بهعلومات تعتبر أكثر ألفةً و معنى مها يسـاعد في على استرجاع المادة التعليمية بشكل أكثر كفاءة.

r. كما يتضح من جدول r r وجود فرق دال إحصائيا عند مستوى ا+ر. بين الطلاب متفاوتي مستوى كفاءة التعلم (منخفض متوسط - مـرتفع) في مدى عامل الذاكرة وذلك بين الطلاب منسفضي ومرتفعي كفاءة التعلهم لصالح المرتفعين، وكذلك وجود فرق دال إحصائيا عند مستوى ا+., بين الطلاب منسفضي و متتوسطي كفاءة

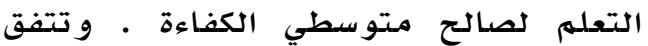
النتيجة السـابقة بشكل عام مـع مـا أشـارت 2003 Bourke \& ) إليه نتائج دراسة ‘Demarie et al., 2004 Adams Thompson \& Gathercole .Wilding; Bernice \& Jennie:2006 2008،2007; Dolores

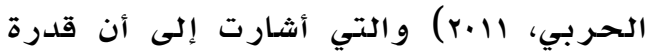
الهتعلهم على تهييز اكبر عدد مــكن مـن العناصر أوالوحدات المعرفية التي يتم استيعابها خلال فترة زمنية معينة قد تكون أحد مصدادر الفروق في متفاوتي مستوى كفاءة التعلم م في مختلف الهقررات الدرر اسيـة.

ويهكن القول بان هذه النتيـجة كانت منطقية نظرا لها تؤديه سعة الذاكرة مـن دور هام في عهلية التعلهم، إذ يهكن فهم هذه النتيجهة عبر فهم أن الطلاب متوسطي ومـرتفعي كفاءة التعلم قد يستخدمون مـجمو عة من الاستر اتيـجيات المعرفية الخاصة بتشفير وتجهيز المعارف و المعلومات الدراسيـة على نحو يسههم في تبني مسجهو عة من المهارات مثل والتنظيم والبحث عن الأسباب و العلاقات القائمهة و المفتر ضية بين مفردات التعلم، وهي مهارات تطلبها عملية الحفظ لئل
يتضح من جدو لا مـا يلي:

ا. وجود فروق دالة إحصائيا عند مستوى ا +, ".

بين الطلاب متفاوتي مستوى كفاءة التعلم على مقاييس الذاكرة البصرية ومدى الذاكرة و الاستعداد الحسـابي و الاستعداد الرياضي و القدرة على العمليـات الحسـابية الضـرورية و مكوني تقدير وظيفة الذاكرة و تقدير استخدام استر اتيجيات التذكر و الهررونة العقلية.

r. عدم و جود فروق دالة إحصائيا بين الطلاب

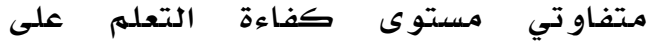
الهكون الماورائي الذاكري تقدير الرضا ضاكيا عن الذاكرة. و لهعرفة لهن هذه الفروق تم إجراء تحليل المقارنات البعدية بطريقة شيفيه Scheffe بين متفاوتي مستوى ميك كفاءة التعلهم على مقاييس الذاكرة

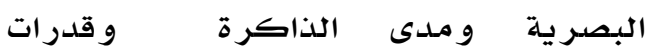
الاستدلال العام ومكونات مـا وراء الذاكرة والهرونة العقلية. ويتضح من جدول اتجاهات تلك الفروق والتي كانت على النحو الآتي:

وجود فرق دال إحصائيا عند مستوى ا+,. بين الطلاب متفاوتي مستتوى كفاءة التعلم (منخفض - مـتوسط - مـرتفع ) في عامل الذاكرة البصرية وذلك بين الطلاب منخفضي ومـرتفعي كفاءة التعلم لصدالح الهـرتفعين، و كذلك وجود فرق دال إحصائيا عند مستوى ا+, بين الطلاب منخفضي ومتوسطي كفاءة التعلم لصسالح متوسطي الكفاءة. وتتفق النتيـجة السابقة بشكل Damico \& عام مـع مـا أشـارت إليـه نتائج دراسـة ،Holmes \& Adams : Guarnera, 2005) 2006؛ السيد، ^^.r؛ Larsen, 2011 ؛ أبوزيد وو اعر، 11 +r) و التي أشارت إلى أن عامل الذاكرة البصرية يعد من أكثر العمليات المعرفية التي تعتبر من مصدادر الفروق بين الطلاب في الهستوى التحصيلي. و يهكن القول بـان هذه النتيجة كانت منطقية نظراً لهـا تؤديه الذاكرة 


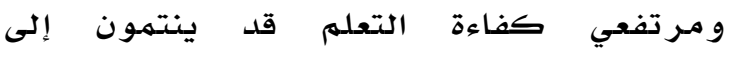
تخصصات علمية تتضهن مقررات دراسية تنهي

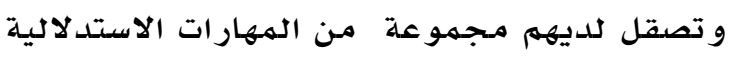
على نحو متكرر و أكثر فعالية في حل المشكلات و الوصول إلى اتخاذ القرار ات أو إصدار الأحكام.

يتضح من جدول r و وجود فرق دال إحصائيا عند مستوى •،1، · بين الطلاب متفاو تي مستوى كفول كفاءة

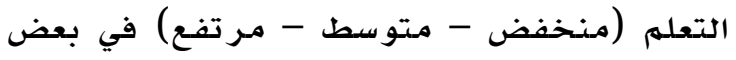

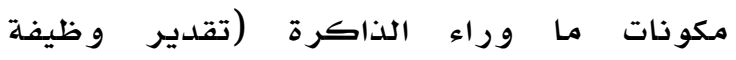

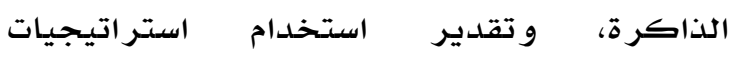

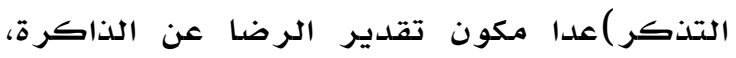
و ذلك بين الطلاب منخفضي ومرتفعي كفاءة

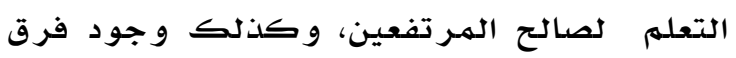
دال إحصائيا عند مستوى ،1، بـ بين الطلاب

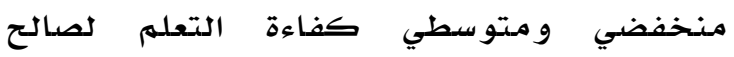

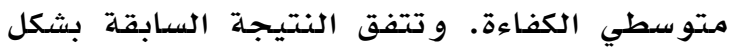

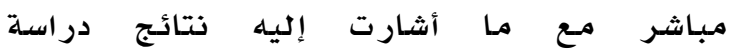

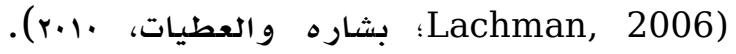

وبشكل غير مباشر مـع نتائج دراسة (

Horton, 2009 ؛Arbuthnott, 2009 Julius, 2012 :Schwartz \& Efklides, 2012 (Kalaimathi \&

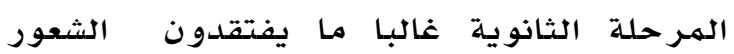
بالرضا عن قدراتهم التذكرية. ويمكن القول بان هذه النتيجة كانت منطقية ويمكن تفسير ها في ضدو اعتبار مكونات مـا وراء الذاكرة إحدى الحى

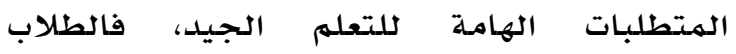

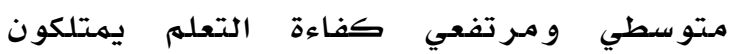

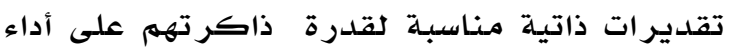
وظائفها اليومية بفعالية دون أخطاء، وتقدير منياس

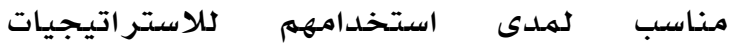
و مساعدات التذكر المختلفة. وهذا من من شأنه

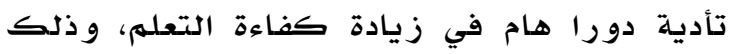

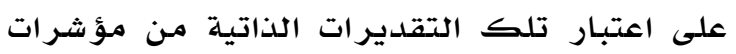

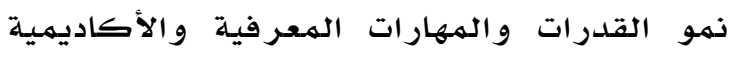

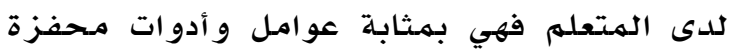

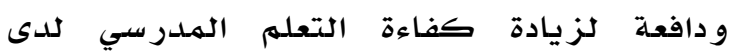
المتعلهم وهوما ينعكس بالضرورة على مستوى

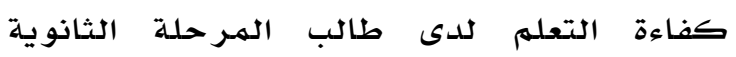
بالإيجاب.

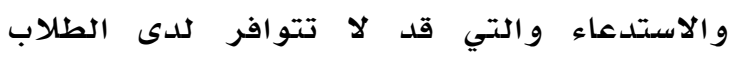
منخفضي كفاءة التعله. و يمكن القول بأنه هذه

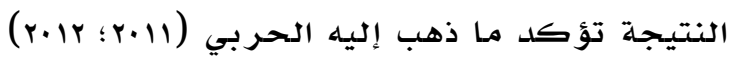

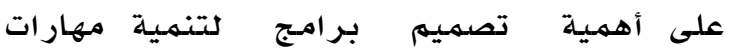

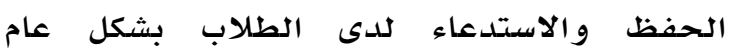
ويتضح ذلك بشكل مباشر في كيفية معالجة الأفكار و تكوين تكوين المدرركات و التعامل مـع مئع

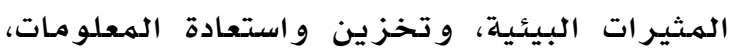

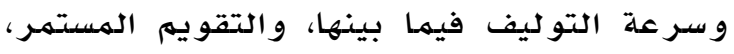

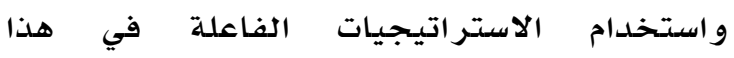
الاستدعاء.

يتضح من جدول r وجود فرق دال إحصائيا عند

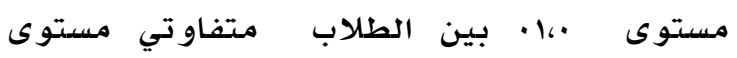
كفاءة التعلهم (منخفض - متوسط - مـرتفع ) في

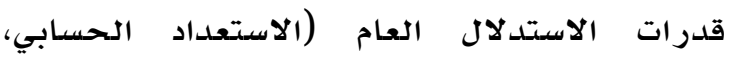

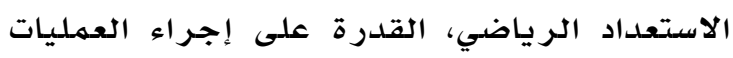

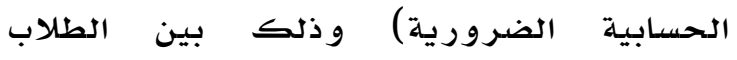

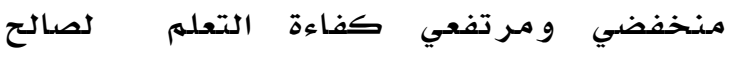
المر تفعين، وكذلك وجود فرق دال إحصائيا

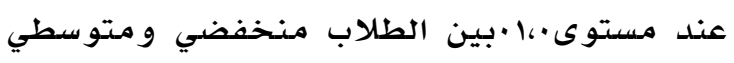

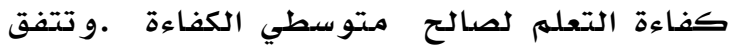

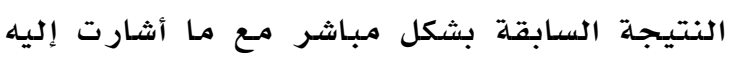

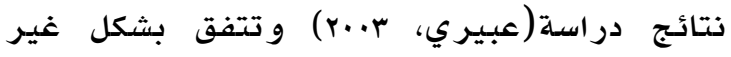

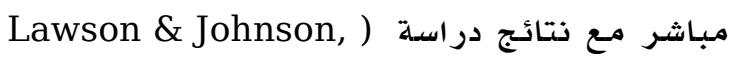
Stenberg Varua ؛ 2008،McDonald 2004

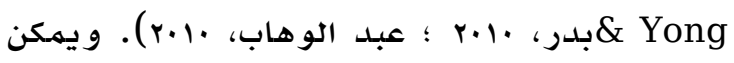
القول بان هذه النتيجة كانت منطقية ويمكن تفسير ها في ضوء اعتبار قدرات الاستدلال العام

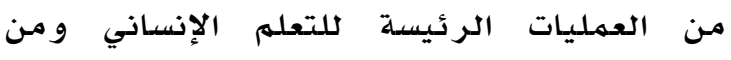

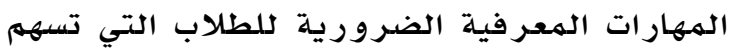
في تقديم تفسيرات دقيقة ومنطقية لأحداث

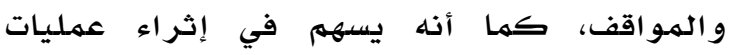

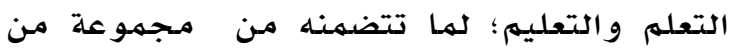

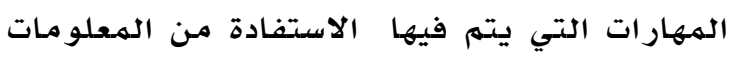
المتاحة في الكثف عن نتائج جديدة، ولفهم الحقائق و المعارف الخاصدة بمختلف فروع العلوم

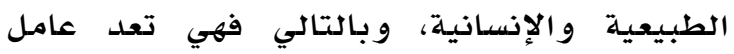

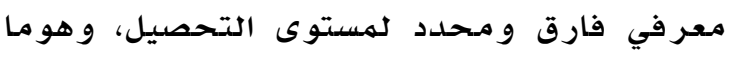
أكدته النتيجة السابقة. ويمكن فهم النتيجة السـابقة مـن خلال إدراك أن الطلاب متوسطي 
الذاكرة وقدرات الاستدلال العام ومكونات ما وراء الذاكرة والمرونة العقلية في التنبؤ بكفاءة التعلم للى طلاب الدرة المرحلة الثانوية؟؟. و لإِجابة على هذا التساؤل تم استخدام تحليل

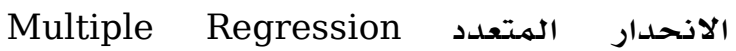

Stepwise باستخدام طريقة Analysis وظهرت النتائج كما في الجدول التالي. جدول باسن

Stepwise تحليل الانحار باستخدام طريقة

\begin{tabular}{|c|c|c|c|c|}
\hline مستوى & قيمة "ف" & متوسط المربعات & درجات & مصدر التباين \\
\hline \multirow[t]{3}{*}{$\cdot, \cdot \cdot$} & $\leq 0 \curlyvee \wedge, \vee 90$ & $118,1.7$ & 7 & الانحدار (التأثير) \\
\hline & & $\cdot, r \circ 9$ & 190 & البواقي \\
\hline & & & $r .1$ & المجموع \\
\hline
\end{tabular}

جدول ؛

معامل تحديد انحار المتغير التابع على المتغيرات المستقلة

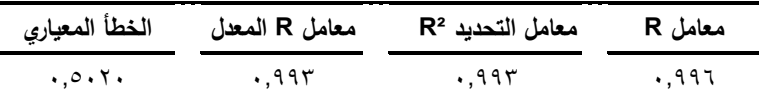

يتبين من جدولع أن معامل تحديد انحدار

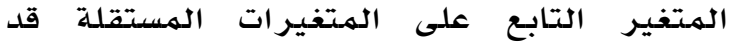

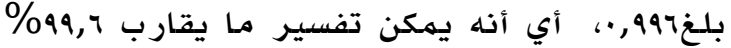
من التباين على متغير كفاءة التعلهم لدى طلاب

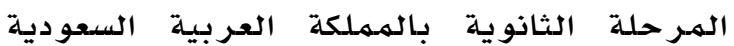
وذلك بمعر فة الذاكرة البصرية و مدى الذاكرة

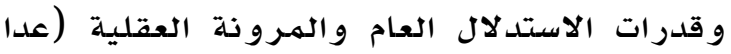

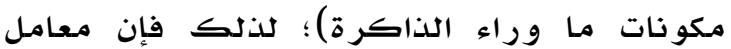

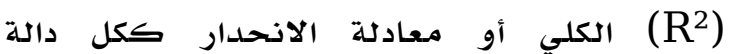

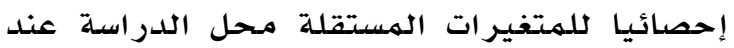
مستوى دلالة ا+,• و يوضح الجدول التالي انحدار المتغير التابع على المتتغيرات المستقلة.
يتضح من جدول r و وجود فرق دال إحصائيا عند مستوى •،1 + بين الطلاب متفاوتي مستوى كفاءة

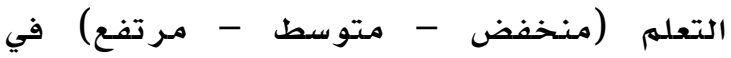
الهرونة العقلية ووذلك بين الطلاب منخفضي و مـرتفعي كفاءة التعلهم لصـالح الهرتفعين،

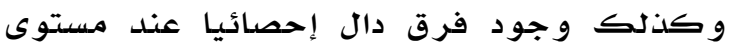
•1، بـ بين الطلاب منخفضي و متوسطي كفاءة التعلم لصسالح متوسطي الكفاءة. وتتفق النتيجة السابقة بشكل غير مباشر مـع ما أشارت إليه

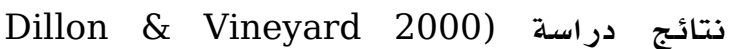
Eagle, 2004 ؛Kalish2004,؛ Bressel, 2003 Q Bing, : Li Meihua \& Bai Xuejun, 2005

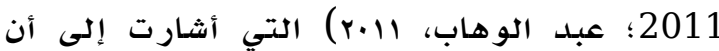
الهروونة العقلية كعامل يسهم في تحسين كفاءة

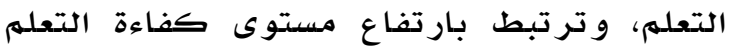
في مختلف المقررات الدراسية و يمكن القول بـان النتيجة السابقة كانت منطقية ويمكن تفسيرها

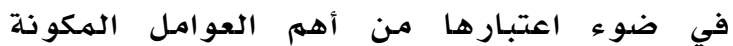
للقدرة على التفكير الابتكاري، ومن المتطلبات

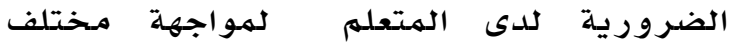

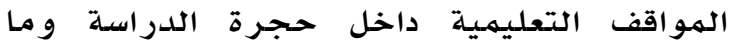
يترتب عليها من متغيرات تتضهمن تحليل عمليات

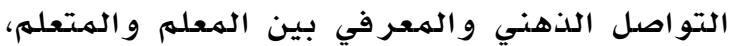
فالطلاب متوسطي ومرتفعي كفاءة التعلم يتصفون بامتلاك مرونة عقلية عالية هم الذين يقومون بتوليد ذاتي للمعرفة من خلال التعديل

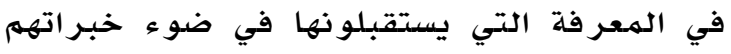

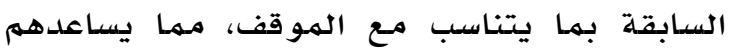
على التحر ك الذهني في زوايا متعددة. نص السؤال الثاني من الدراسـة الحالية على: ما القيمة التنبؤية لكل من الذاكرة البصرية ومدى

- جدول

Stepwise تحليل الانحدار باستخدام طريقة

\begin{tabular}{|c|c|c|c|c|c|}
\hline مستوى الدلالة & قيمة"ت" & بيتا Beta & الخطأ المعياري & B المعامل البائي B & المتغيرات المستقلة \\
\hline$\cdot, \cdots$ & $\varepsilon, \wedge \wedge$ & & . ros & $1, \vee<q$ & ثابت الانحدار \\
\hline$\cdot, \cdots$ & r,9० & . זצ. & $\cdot, \cdot 77$ & •,Yדו & عامل الذاكرة البصرية \\
\hline$\cdot, \cdots$ & $V, Y_{O}$ & ס ס ז, • & $\cdot, \cdot r q$ & • & عامل مدى الذاكرة \\
\hline$\cdot, \cdots$ & $0, r q$ & דוז, &., .09 & $\cdot, 11 \mathrm{r}$ & الاستعداد الحسابي \\
\hline$\cdot, \cdots$ & $r, v i$ & $\cdot, 1 \cdot 1$ & $\cdot, \cdot r$. & $\cdot, \cdot \times 1$ & الاستعداد الرياضي \\
\hline$\cdot, \cdot 1$ & r ז & $\cdot, 1 \leq r$ & $\cdot, \cdot Y_{1}$ & • & العمليات الحسابية \\
\hline$\cdot, \cdot 1$ & $r, \cdot T$. & $\cdot|v|$ & $\cdot, \cdot V_{7}$ & $\cdot, 1 \leq V$ & المرونة العقلية \\
\hline
\end{tabular}


والقدرة على فهم الهعاني وفهم وتركيب

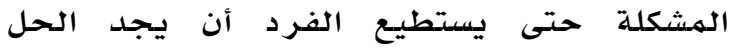

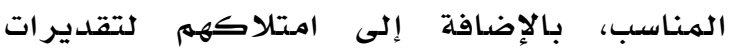

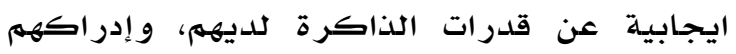
لها بما يضهنه هذا الرضا من انفعالات كالثقة

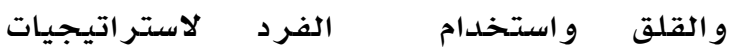
و مساعدات التذكر المختلفة، و القدرة على إنتاج

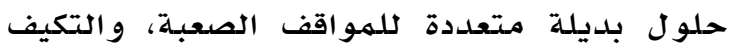

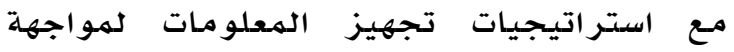
ظروف جديدة وغير متوقعة عادة ما يكونون

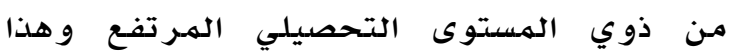
يؤكد على أهمية تصميهم وتنفيذ بر امـج تدربيبة

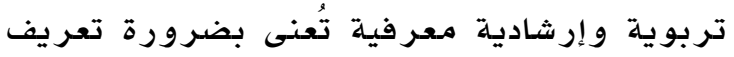
و تلدريب طلاب الهـرحلة الثانوية بالمهملكة العربية السعودية على استخدام استراتيجيات

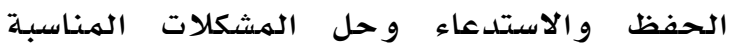
و الفاعلة في الحياة اليومية و الأكاديمية.

التوصيات

ا. ضرورة الاهتمـام ببـر امـج تتنميسة مهـارات

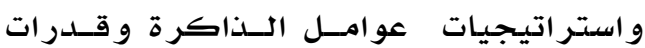

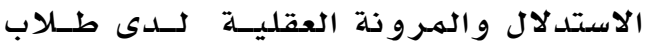

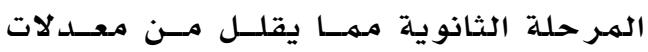

الهــدر التـربـوي وزيــادة جــودة مخر جــات

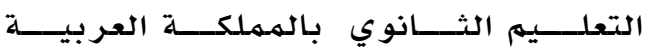

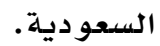

Y. إجــر اء الهز يــــ مــن الأبحسـاث فـي البيئسـة

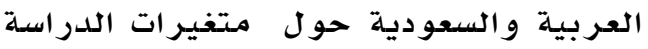

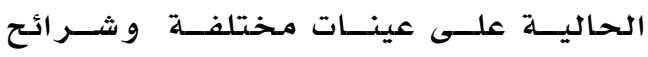

عمرية مختلفة بالمـملكة العربية السعودية. r. دراسـة فاعلية بر نامـج معرفي لتنهية كفاءة

التعلهم وفق متطلبات استر اتيجيات الذاكرة

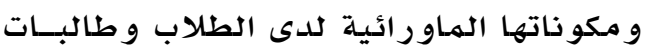

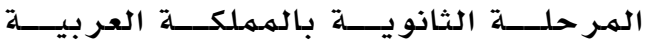

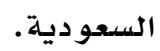

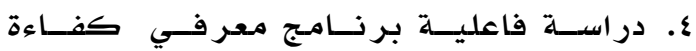

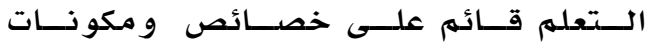

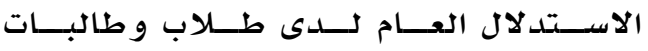

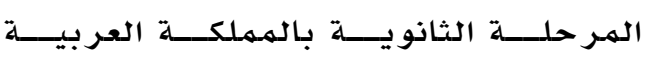

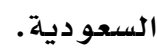

و من خلال جلدول ه يمكن مـلاحظة ثابت الانحدار و معاملات الانحدار المبينة في عامود المعامل البائي B، و بالتالي تكون معادلة الانحدار المقدرة الهدئل كمها يلي: كفاءة التعلهم = (عامل الذاكرة

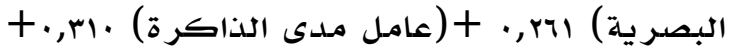

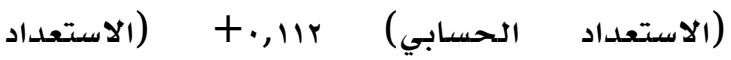

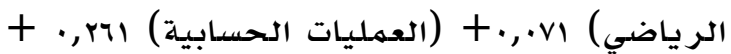

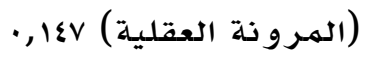

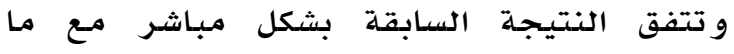
Kulp; Edwards \& أشارت إليه نتائج دراسة الية Holmes \& Adams, ؛Mitchel, 2002) 2006؛ (Sarver et al , 2012) و التي أشارت إلى أن عامل الذاكرة البصرية يعد منبئًا جيدا بالتحصيل، و متفقة مـع نتائج دراسـة ( Alloway \& Alloway , 2010; Bull; Espy \& Wiebe, 2008) و التي أشارت إلى أن عامل مدلى الذاكرة يعد منبئا جيدا بالتحصيل، ومتفقة أيضا مـع نتائج دراسـة (Lawson \& Johnson, 2004) Stenberg Varua \& : McDonald, 2008

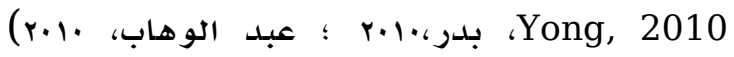
و التي أشارت إلى أن قدرات الاستدلال العام تعد لـدابل

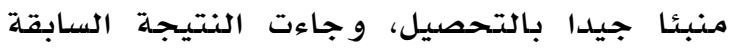

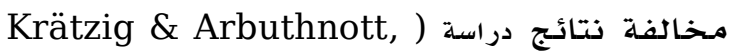
Schwartz \& ؛ Horton, 2009؛2009 Julius, 2012 ؛ Efklides , 2012 (Kalaimathi \& والتي أشارت إلى أن مكونات

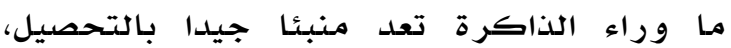

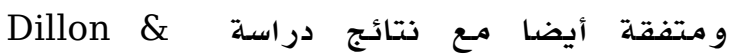
Kalish, : Bressel, 2003؛ Vineyard 2000) Li Meihua \& Bai : Eagle, 2004 2004 2005 .$(r \cdot 1)$

و يفسر الباحث هذه النتيجة إلى أن كفاءة

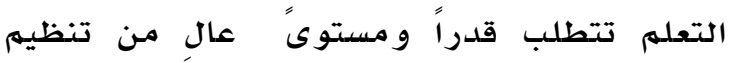

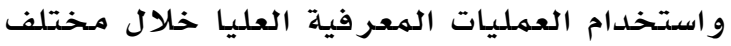
مواقف التعلهم، وبالتالي فالطلاب ذوي مستويات

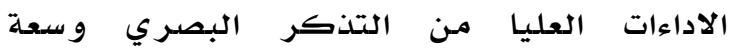

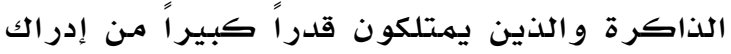
العلاقات التي تربط بين الأشياء، و يمتلكون 
بشــارة، موفـق و العطيـات، خالــــ (.1.r). أثـر

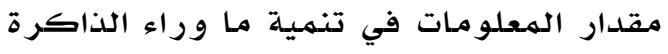

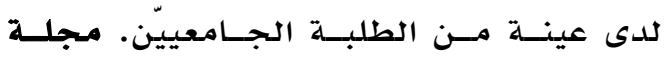
جامعة النجاح لكلابحاث (العلوم الإنسـانية)، .VrA-7qr ، r r $r \varepsilon$

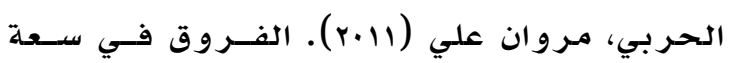

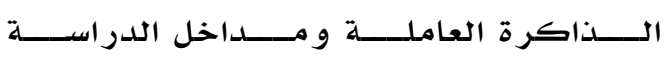

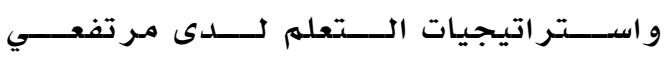

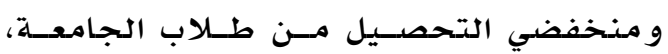

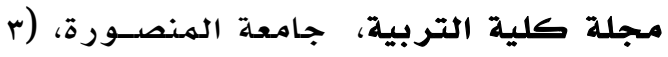

$$
\text { .19.-1ra، (vo) }
$$

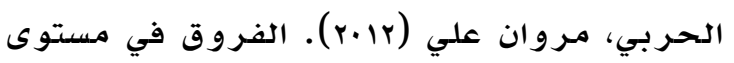

تجهيز المعلومات لدى مرتفعي ومنخفضيسي

سعة الذاكرة في ضوء الختلاف استر اتيجيات

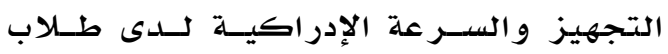

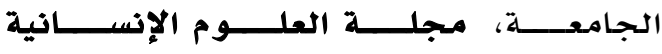

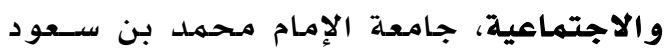

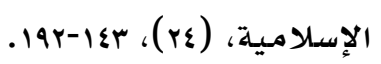

الحربي، مروان علي (rا.r). أثر تفاعل السيطرة المخيـة ومسـتوى فاعليـة الــذات علـى أداء

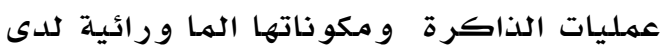

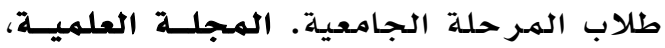

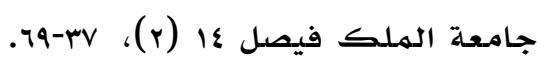

حسـام الـدين، ليلـى عبــد الله (.l.r). تصسحيح

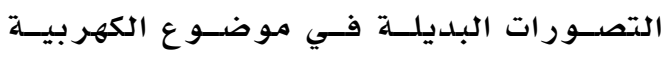

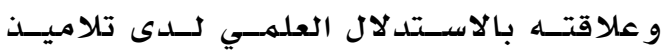
الصف الثالث الإعدادي. دراسات فى المنــاهج

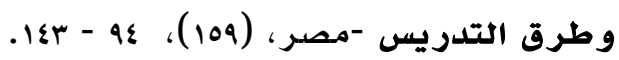
خليسل، نــوال عبــد الفتـاح فهمـي (rا.r). أثـر

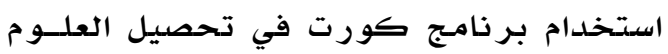

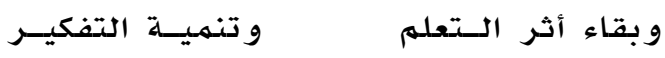

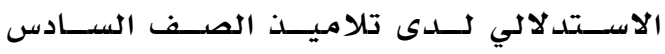

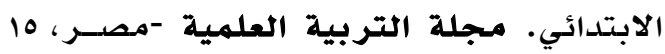

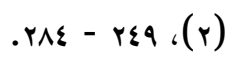

الزيات، فتحي مصطفى (ب...r). الأسس المعرفية

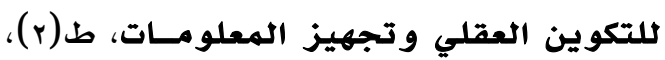
القاهرة: دار النشر للجامعات التجنيز المعلو

\section{المر اجع}

\section{References}

إبر اهيم، فواز (r.v. (r.v). أثر عدد من اسـتراتيجيات

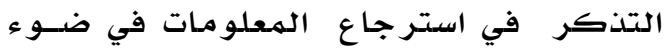

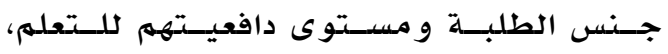

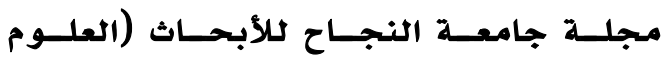

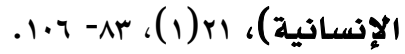

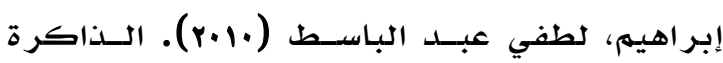

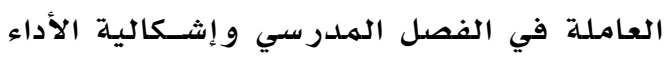

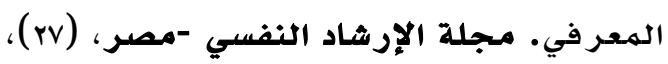
$.19-1$

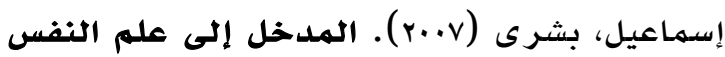

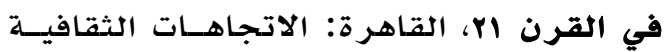
للنشر و التوزيع التون أحمدل، صلاح عبـد السـميع محهــد (.1.ب). أثـر

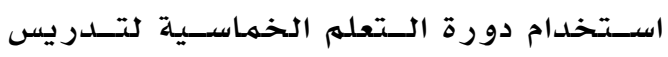

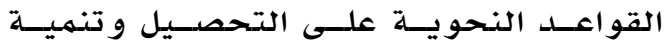

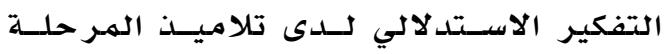
الإعدادية. مجلة القـراءة والمعرفــة، (.11)، $.19 \varepsilon-1 r 9$

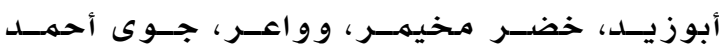

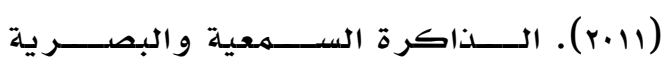

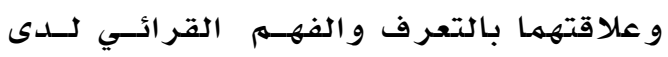

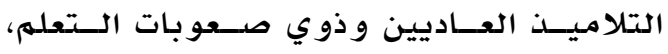

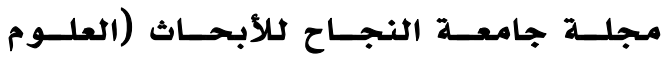
الإنسانية)،

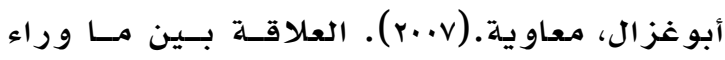

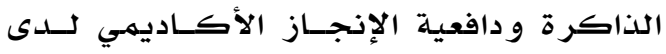

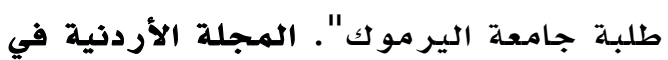

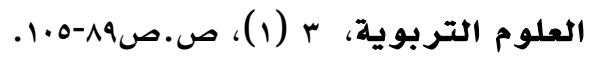

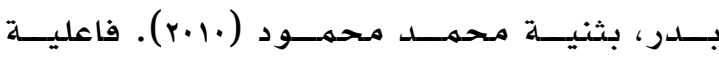

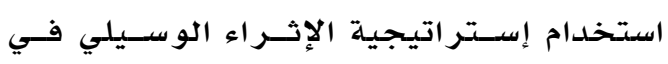

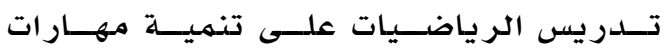

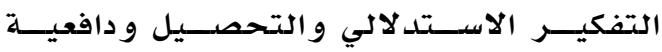

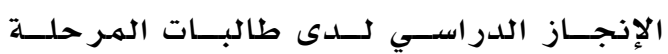

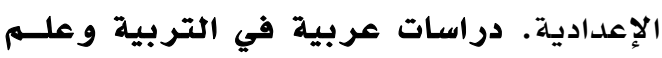
النفس - السعودية، ع( ع)، IIV - 107. 
التدريس بالجامعة. مـجلــة بحــوث التربيـة

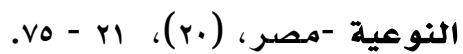

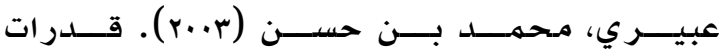

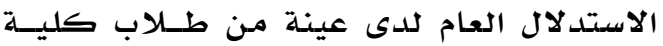

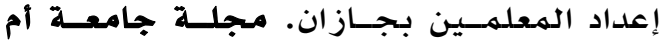

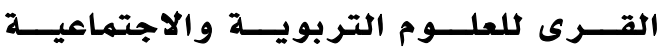

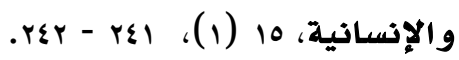

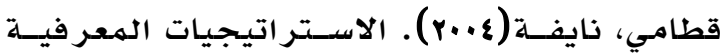

للـتعلم المــنظم ذاتيـاً للطلبــة الجــامعيين،

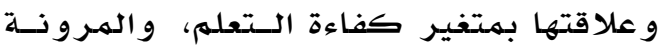

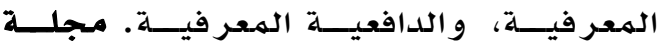

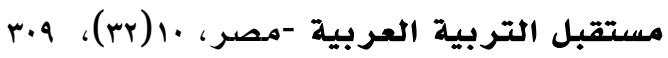

.rя. -

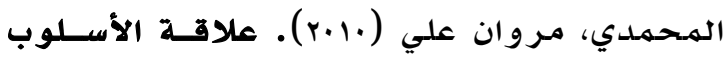

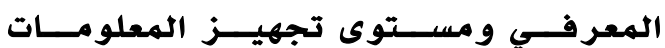

و التخخصـص الدراسـي بالقــلـرة علـى حسل

المشكلات للى طلاب جامعسـة الملسك عبـد

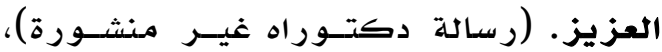

جامعة طيبـة، الهمدينسة المنــورة، الهملكسة

$$
\text { العربية السعودية. }
$$

Alloway, T. P. \& Alloway, R. G. (2010). Investigating the predictive roles of working memory and IQ in academic attainment. Journal of Experimental Child Psychology, 106, 20-29.

Abrahams, F.; Friedrich, C. \& Tredoux, N. (2012). Selection of postgraduate students in a south African management programmed: How Effective Is the General Reasoning Test, industry and Higher Education, 26(2), 139-149.

Bird, L. (2010). Logical reasoning ability and student performance in general chemistry, Journal of Chemical Education, 87(5), 541546.

Bourke, L. \& Adams, A. (2003). The relationship between working memory and early writing assessed at the word, sentence and text level, Educational and Child Psychology, 20(3), 19-35.

Bull, R; Espy, K \& Wiebe, S. (2008). Short-term memory, working memory and executive

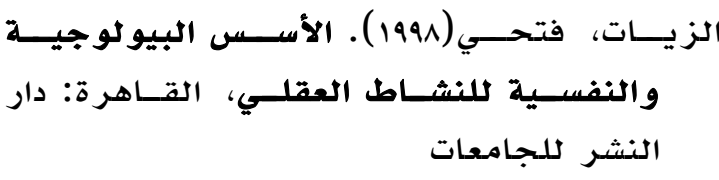

سليمان، سميحة محمد سعيد(r) (r)). القدرة على التفكير الاستدلالي وعلاقتها بكفـاءة الـتعلهم

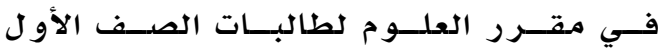

الإعدادي بمحافظة الطائف. مـلــــة التربيـة

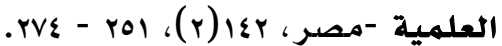

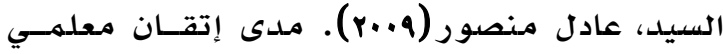

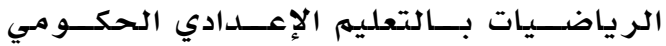

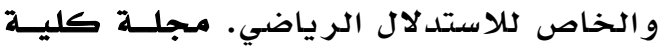

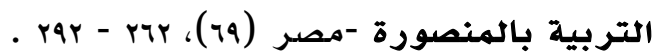

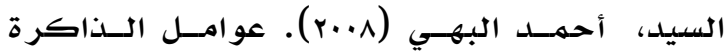

و علاقتها بأسـاليب الاسـتـذكار والـذكاءات

المتعــددة لــدى بعـض طـلاب إعـــاد معلــم

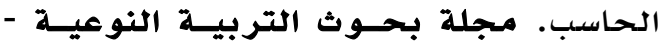

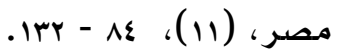

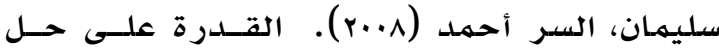

المشكلات و علاقتها ببعض المتغيـرات لــدى

عينة مـن طـلاب كليــة المعلهـين بحـائـل،

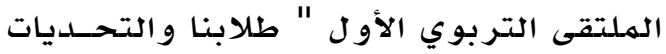

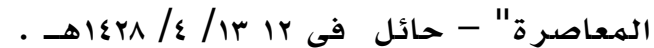

الشـيخ، ســليمـان الخضــري، والشـرقاوي، أنــور

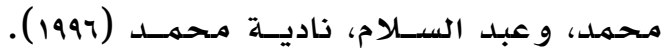

بطاريــة الاختبــارات المعرفيـة، القــاهرة:

مكتبة الأنجلو المصرية.

الشرقاوي، أنـور(ب.r.r).علــم الــنفس المعرفـي

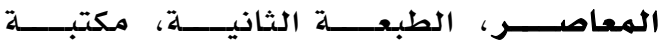
الأنجلوالمصريـة، القاهرة، مصر.

عبد الوهـاب، عبيـر شـفيق محمهـد (·r.r). أثـر

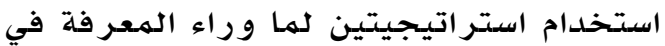

تحصــيل مـــادة علـــم الـــفس و التفكيــــر

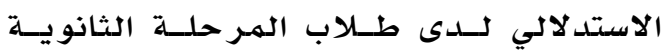

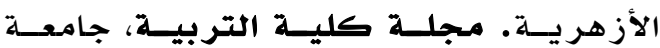

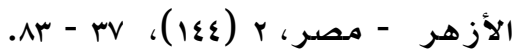

عبد الوهاب، صلاح شريف (11) (ب). الهـرونـة

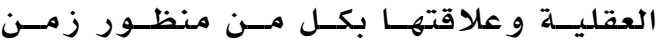

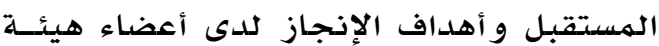


Bressel, E. (2003). A neuromechanical analysis of a novel leg movement trajectory. Dissertation Abstracts International, 59 (3) 66763

D.J. Tippins \& A.J. Steward (Eds.), Assessing schools for generation $R$ (Responsibility): $A$ guide to legislation and school policy in science education, The Netherlands: Springer.

D'Amico, A. and Guarnera, M. (2005). Exploring working memory in children with low arithmetical achievement, Learning and Individual Differences, 15(3), 189-202.

DeMarie, D; Aloise-Young, P; Prideaux, C; Muransky-Doran, J \& Gerda J. (2004). College students' memory for vocabulary in their majors: evidence for a nonlinear relation between knowledge and memory, Canadian Journal of Experimental Psychology, 58(3), 181-95

Dillon, Ronna \& Vineyard, George. (2000). Cognitive flexibility: further validation of flexible combination, Retrieved October 23, 2013, from http://eric.ed.gov/?id=ED435727.

Dolores, H. (2008). Is working memory capacity diminished in students with low academic achievement?, Clinical Neurophysiology, 119( 9), 1939-2170

Eagle, L. (2004). Education reforms: The marketisation of education in New Zealand.

Epps, W. (2003). Understanding and overcoming barriers to the use of Computers in classroom instruction at University of California, Los Angeles. Higher Education, 66 (1), 7-28.

Flavell, J. (2003). Development of children's knowledge about the mind 2003, Heinz Werner Lecture Series, 25, Worcester, MA: Clark University Press

functioning in preschoolers longitudinal predictors of mathematical achievement at age 7 years in developmental,

Neuropsychology journal, 33(3), 205-228.

Holmes J. \& Adams, J. (2006). Working memory and children's mathematical skills Implications for mathematical development and mathematical curricula. Educational Psychology, 26, 339-366.
Horton, C. (2009). Metamemory in the classroom: Judgements of learning and academic achievement. Cognitive Psychology Section 26th Annual Conference, 1-3rd Sept 2009, University of Hertfordshire. Abstract published: BPS Proceeding.

Kalaimath, H. \& Julius, A. (2012). Effect of metamemory strategies on learning biochemical cycle among higher secondary school students, Indian Journal of Applied Research, 2(1), 3-5.

Kalish, A. (2004). Learning to profess: The enculturation of new faculty members in English. Dissertation Abstracts International, 58 (9) 3438.

Kaufman, S., DeYoungb C., Reisc D. \& Grayc, J. (2011). General intelligence predicts reasoning ability even for evolutionarily familiar content, Intelligence, 39 (5), 311322

Krätzig, G. \& Arbuthnott, K. (2009). Metacognitive learning: The effect of itemspecific experience and age on metamemory calibration and planning. Metacognition and Learning،(4), 125-144.

Kulp, M; Edwards, K \& Mitchell G. (2002). Is visual memory predictive of belowaverage academic achievement in second through fourth graders?, Optometry and Vision Science, 79(7), 431-434.

Lachman, M. (2006). Perceived control over aging-related declines: Adaptive beliefs and behaviors. Current Directions in Psychological Science, 15, 282-286.

Lawson, A \& Johnson, M. (2004). "The validity of kolb learning styles and neopiagetion development levels in collage biology". Journal of Research in Science Teaching. (27). 79- 90.

Martinussen, R., Hayden, J. Johnson S. \& Tannock, R.(2005). A meta-analysis of working memory impairments in children with attention-deficit/hyperactivity disorder, Journal of the American Academy of Child and Adolescent, 44(4):377.

McDonald, Betty. (2008). Predicting mathematical aptitude for higher education. International Journal of Mathematical Education in Science $\mathcal{E}$ Technology, 39(3), 293-299. 
McNamara, J. \& Wong, B. (2003). Memory for everyday information in students with learning disabilities. Journal of Learning Disabilities, 36(5), 394-406 .

Qi Bing, Liu. (2011). Relationship between cognitive flexibility, learning style and academic achievement of Junior middle school student, Journal of Baoding University،(6), 100-105.

Rawson, K. A., Dunlosky, J., \& Thiede, K. W. (2000). The rereading effect: Metacom prehension accuracy improves across reading trials. Memory $\mathcal{E}$ Cognition, 28, 1004-1010.

Sarver, Dustin, et al (2012). Attention problems, phonological short-term memory, and visions partial short-term Memory: differential effects on near- and long-term scholastic achievement, Learning and Individual Differences 22(1), 8-19.

Schwartz, B. L., \& Efklides, A. (2012). Met memory and Memory efficiency: Implications for student learning. Journal of Applied Research in Memory and Cognition1, (3), 145 - 151.

Spelke, Elizabeth. (Dec. 2005). Sex differences in intrinsic aptitude for mathematics and science? American Psychologist, 60(9), 950958.

Stenberg, L., Varua, M \& Yong, J. (2010). Mathematics aptitude, attitude, secondary schools and student success in quantitative methods for business subject in an Australian Catholic university experience. Paper presented at the 39th Australian Conference of Economists. Sydney, NSW, 27-29 September.

Tchanturia, K; Anderluh, M; Morris, R; RabeHesketh, S; Collier, D; Sanchez, P \& Treasure, J.(2004). Cognitive flexibility in anorexia nervosa and bulimia nervosa, Journal of the International Neuropsychological Society, 10(4), 513.

Thompson, S. \& Gathercole, S. (2006). Executive functions and achievements on national curriculum tests: Shifting, updating, inhibition and working memory. Quarterly Journal of Experimental Psychology, (59), 745-759.

Torry, M. (2003). Comparison of center of pressure and center of gravity path variability between younger and older adult men during single support gait, Retrieved October 23, 2013, from http://classify.oclc.org/classify2/Classify Demo?owi=9761093

Troche, S. \& Rammsayer, T. (2009) .The Influence of Temporal Resolution Power and Working Memory Capacity on Psychometric Intelligence. Intelligence, 37(5), 479-486.

Troyer, A. \& Rich, J. (2002). Psychometric properties of a new metamemory questionnaire for older adults, The journals of gerontology. Series B, Psychological sciences, 57(1), 19-27.

Wilding, J. Bernice, A \& Jennie, H. (2007). Relations between life difficulties, measures of working memory operation, and examination performance in a student sample, Psychological Press, 15(1), 57-62. 